\title{
Rapid Synthesis of Primary Arylselenoamides by Reaction of Aryl Nitriles with Woollins Reagent
}

\author{
Guoxiong Hua, Yang Li, Alexandra M .Z. Slawin, and J. Derek Woollins* \\ School of Chemistry, University of St Andrews, Fife, KY16 9ST (Great Britain)
}

\section{Supporting information}

\section{Experimental Section}

All reactions were performed under a dinitrogen atmosphere by using standard Schlenk line techniques, subsequent chromatographic and work up procedures were performed in air. Infrared spectra were recorded as $\mathrm{KBr}$ discs in the range $4000-250 \mathrm{~cm}^{-1}$ on a PerkinElmer System 2000 Fourier-Transform spectrometer. ${ }^{1} \mathrm{H},{ }^{13} \mathrm{C}$ and ${ }^{77} \mathrm{Se}$ NMR spectra were recorded using a Jeol Delta GSX-270 FT NMR spectrometer. Microanalyses were performed by the University of St Andrews microanalysis service and mass spectra were carried out in CI mode by University of St Andrews mass spectrometer service. 
Table 1. Data of Microanalysis and CI MS spectra of 2 - 19

\begin{tabular}{|c|c|c|c|c|}
\hline \multirow[t]{2}{*}{ Compound } & \multicolumn{3}{|c|}{ Microanalysis: \% Found (Calcd) } & \multirow[t]{2}{*}{$\mathrm{CI} \mathrm{MS}, \mathrm{m} / \mathrm{z}$} \\
\hline & $\mathrm{H}$ & $\mathrm{C}$ & $\mathrm{N}$ & \\
\hline $\mathrm{C}_{7} \mathrm{H}_{7} \mathrm{NSe}(\mathbf{2})$ & $3.89(3.83)$ & $45.70(45.67)$ & $7.53(7.61)$ & $185[\mathrm{M}+\mathrm{H}]^{+}$ \\
\hline $\mathrm{C}_{8} \mathrm{H}_{9} \mathrm{NSe}(\mathbf{3})$ & $4.67(4.57)$ & $48.60(48.50)$ & $7.03(7.07)$ & $199[\mathrm{M}+\mathrm{H}]^{+}$ \\
\hline $\mathrm{C}_{8} \mathrm{H}_{9} \mathrm{NSe}(\mathbf{4})$ & $4.59(4.57)$ & $48.55(48.50)$ & $7.15(7.07)$ & $199[\mathrm{M}+\mathrm{H}]^{+}$ \\
\hline $\mathrm{C}_{7} \mathrm{H}_{5} \mathrm{Cl}_{2} \mathrm{NSe}(\mathbf{5})$ & $2.05(1.99)$ & $33.13(33.23)$ & $5.45(5.54)$ & $254[\mathrm{M}+\mathrm{H}]^{+}$ \\
\hline $\mathrm{C}_{8} \mathrm{H}_{6} \mathrm{~N}_{2} \mathrm{Se}(\mathbf{6})$ & $2.90(2.89)$ & $46.02(45.95)$ & $13.49(13.40)$ & $210[\mathrm{M}+\mathrm{H}]^{+}$ \\
\hline $\mathrm{C}_{8} \mathrm{H}_{6} \mathrm{~N}_{2} \mathrm{Se}(7)$ & $2.95(2.89)$ & $45.11(45.95)$ & $13.47(13.40)$ & $210[\mathrm{M}+\mathrm{H}]^{+}$ \\
\hline $\mathrm{C}_{7} \mathrm{H}_{6} \mathrm{~N}_{2} \mathrm{O}_{2} \mathrm{Se}(\mathbf{8})$ & $2.72(2.64)$ & $36.55(36.70)$ & $12.29(12.23)$ & $230[\mathrm{M}+\mathrm{H}]^{+}$ \\
\hline $\mathrm{C}_{9} \mathrm{H}_{11} \mathrm{NO}_{2} \mathrm{Se}(\mathbf{9})$ & $4.58(4.54)$ & 44. $20(44.23)$ & $5.79(5.74)$ & $245[\mathrm{M}+\mathrm{H}]^{+}$ \\
\hline $\mathrm{C}_{9} \mathrm{H}_{11} \mathrm{NO}_{2} \mathrm{Se}(\mathbf{1 0})$ & $4.60(4.54)$ & $44.26(44.23)$ & $5.69(5.74)$ & $245[\mathrm{M}+\mathrm{H}]^{+}$ \\
\hline $\mathrm{C}_{9} \mathrm{H}_{11} \mathrm{NO}_{2} \mathrm{Se}(\mathbf{1 1})$ & $4.57(4.54)$ & $44.37(44.23)$ & $5.80(5.74)$ & $245[\mathrm{M}+\mathrm{H}]^{+}$ \\
\hline $\mathrm{C}_{8} \mathrm{H}_{9} \mathrm{NOSe}(\mathbf{1 2})$ & $4.30(4.24)$ & $44.79(44.87)$ & $6.49(6.54)$ & $215[\mathrm{M}+\mathrm{H}]^{+}$ \\
\hline $\mathrm{C}_{8} \mathrm{H}_{9} \mathrm{NOSe}(\mathbf{1 3})$ & $4.34(4.24)$ & $44.95(44.87)$ & $6.61(6.54)$ & $214[\mathrm{M}+\mathrm{H}]^{+}$ \\
\hline $\mathrm{C}_{8} \mathrm{H}_{9} \mathrm{NOSe}(\mathbf{1 4})$ & $4.29(4.24)$ & 45.01(44.87) & $6.61(6.54)$ & $214[\mathrm{M}+\mathrm{H}]^{+}$ \\
\hline $\mathrm{C}_{7} \mathrm{H}_{5} \mathrm{ClNSe}$ (15) & $2.82(2.77)$ & $38.60(38.47)$ & $6.50(6.41)$ & $219[\mathrm{M}+\mathrm{H}]^{+}$ \\
\hline $\mathrm{C}_{7} \mathrm{H}_{5} \mathrm{ClNSe}(\mathbf{1 6})$ & $2.86(2.77)$ & $38.55(38.47)$ & $6.32(6.41)$ & $219[\mathrm{M}+\mathrm{H}]^{+}$ \\
\hline $\mathrm{C}_{7} \mathrm{H}_{5} \mathrm{ClNSe}$ (17) & $2.85(2.77)$ & $38.37(38.47)$ & $6.47(6.41)$ & $219[\mathrm{M}+\mathrm{H}]^{+}$ \\
\hline $\mathrm{C}_{7} \mathrm{H}_{5} \mathrm{FNSe}$ (18) & $3.05(2.99)$ & $41.56(41.60)$ & $7.01(6.93)$ & $203[\mathrm{M}+\mathrm{H}]^{+}$ \\
\hline $\mathrm{C}_{7} \mathrm{H}_{5} \mathrm{BrNSe}$ (19) & $2.35(2.30)$ & $31.79(31.97)$ & $5.41(5.33)$ & $264[\mathrm{M}+\mathrm{H}]^{+}$ \\
\hline
\end{tabular}


${ }^{1} \mathrm{H},{ }^{13} \mathrm{C}$ and ${ }^{77} \mathrm{Se}$ NMR spectra of $\mathbf{1}$ - 19:

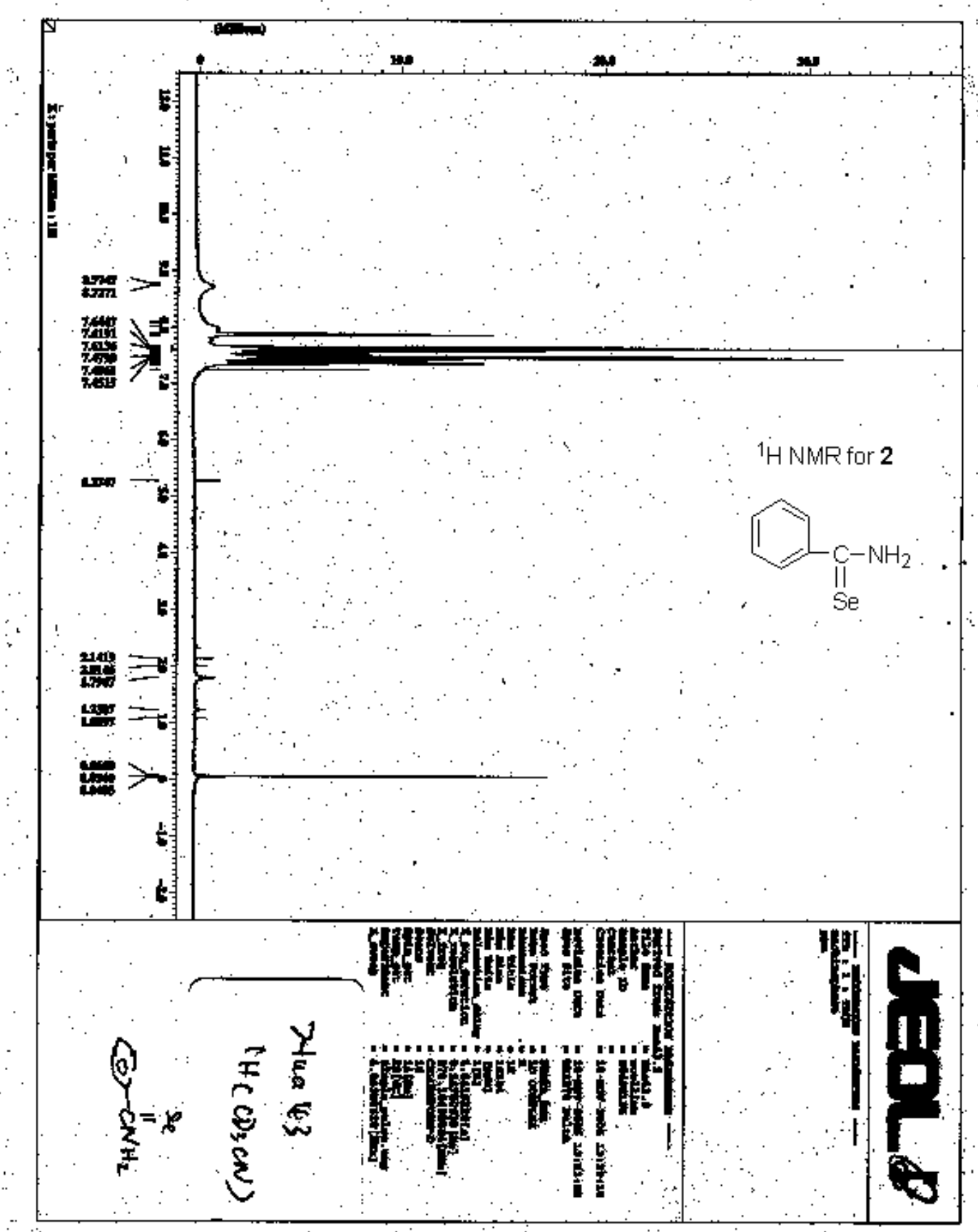




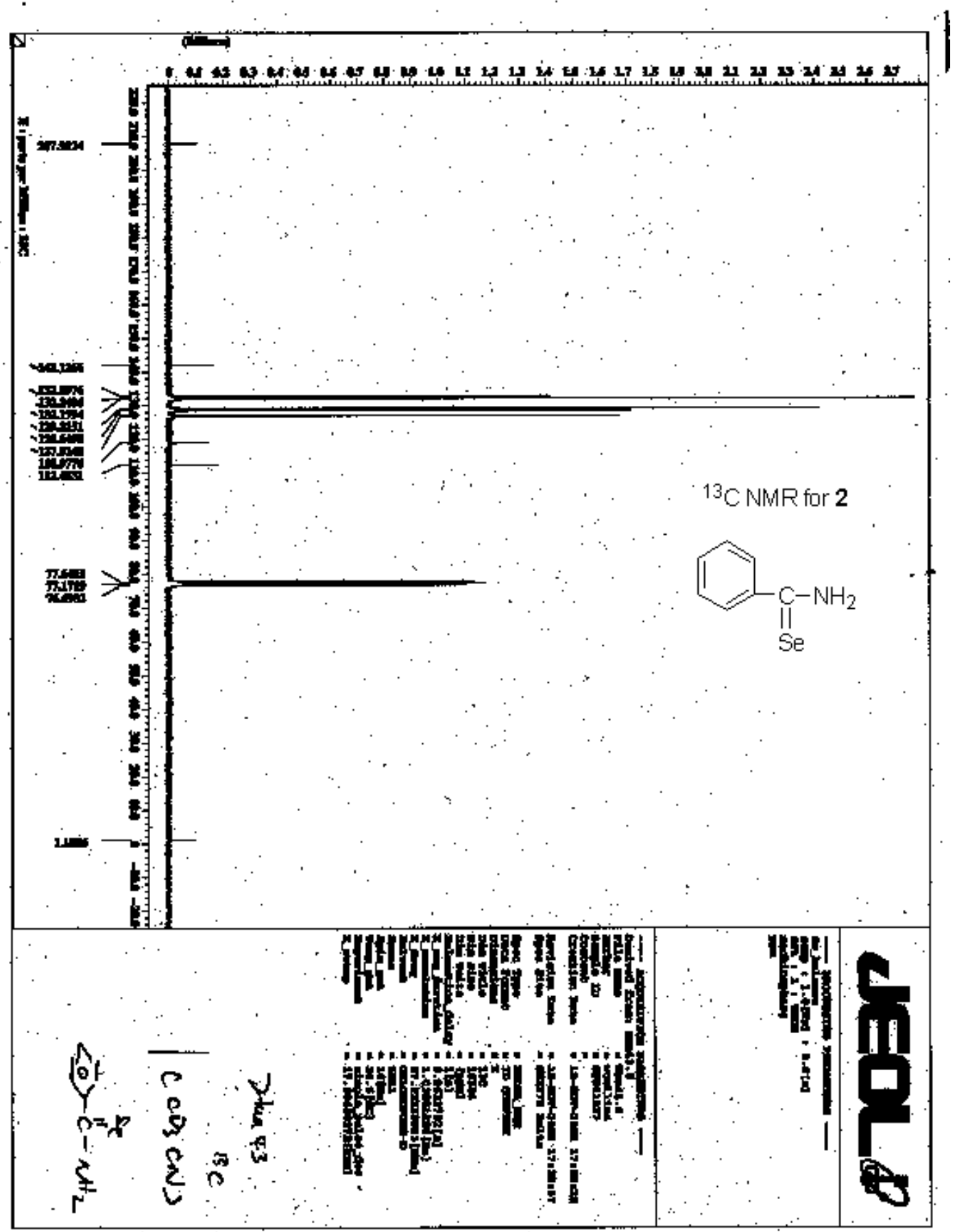




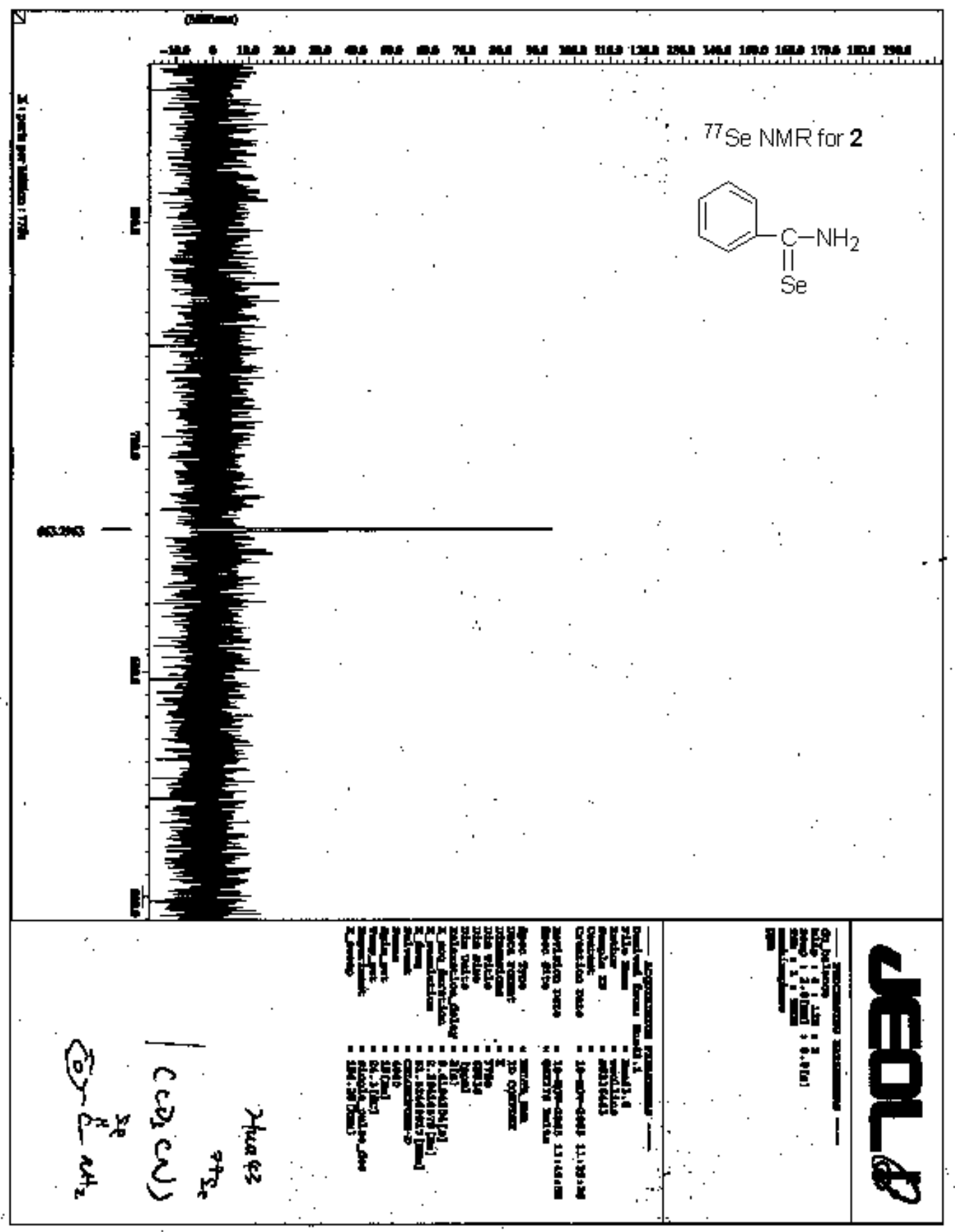




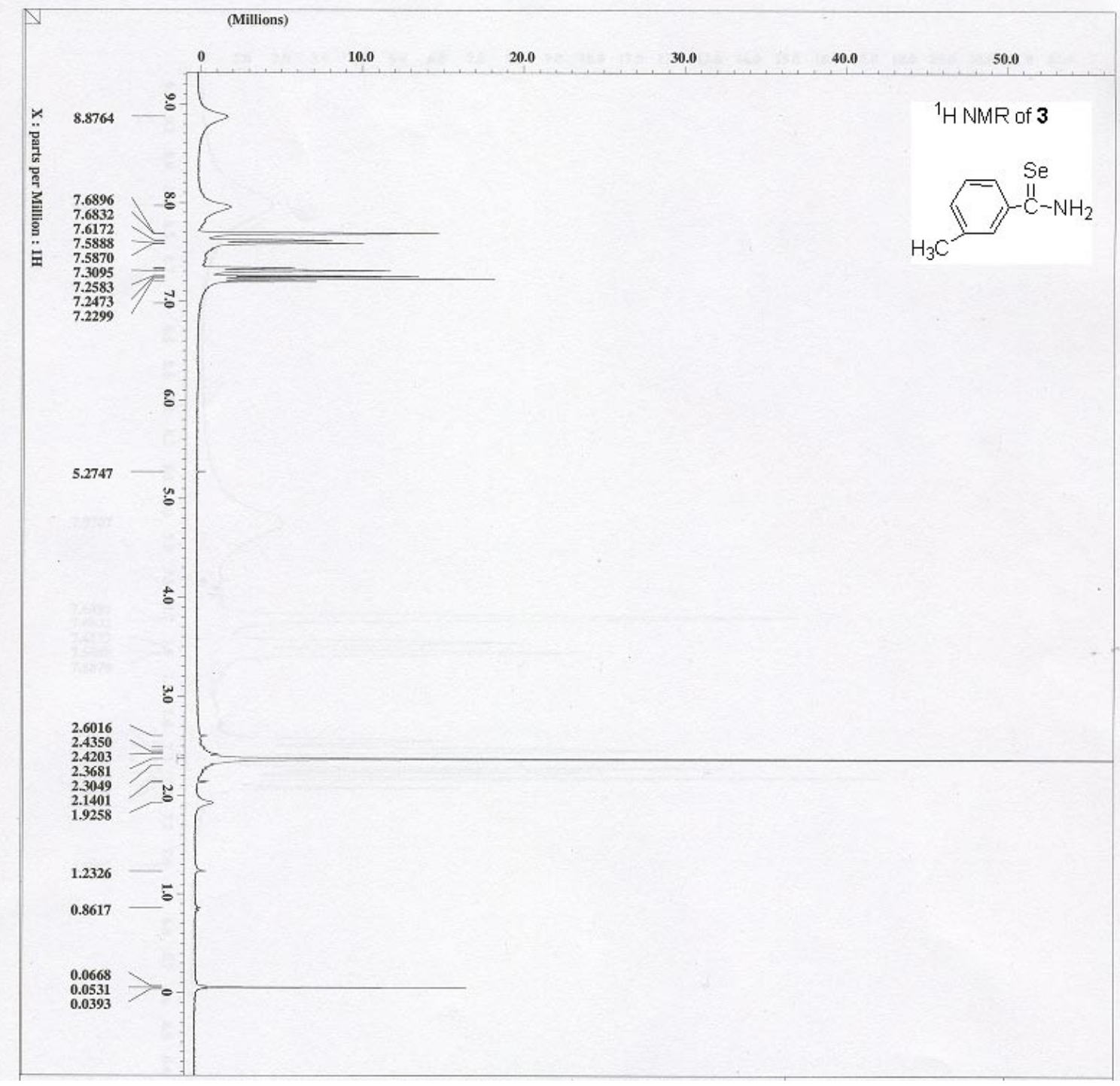




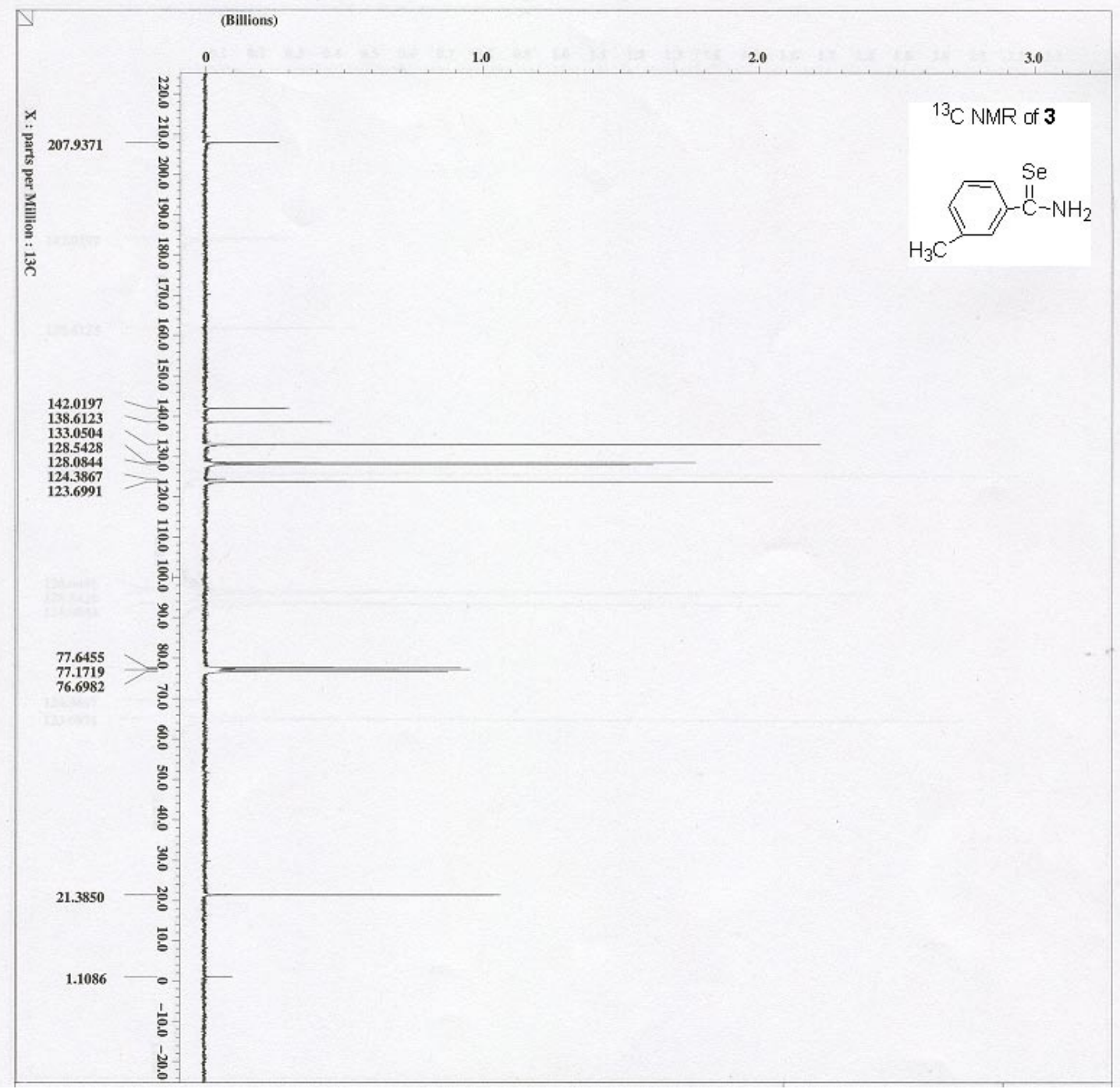




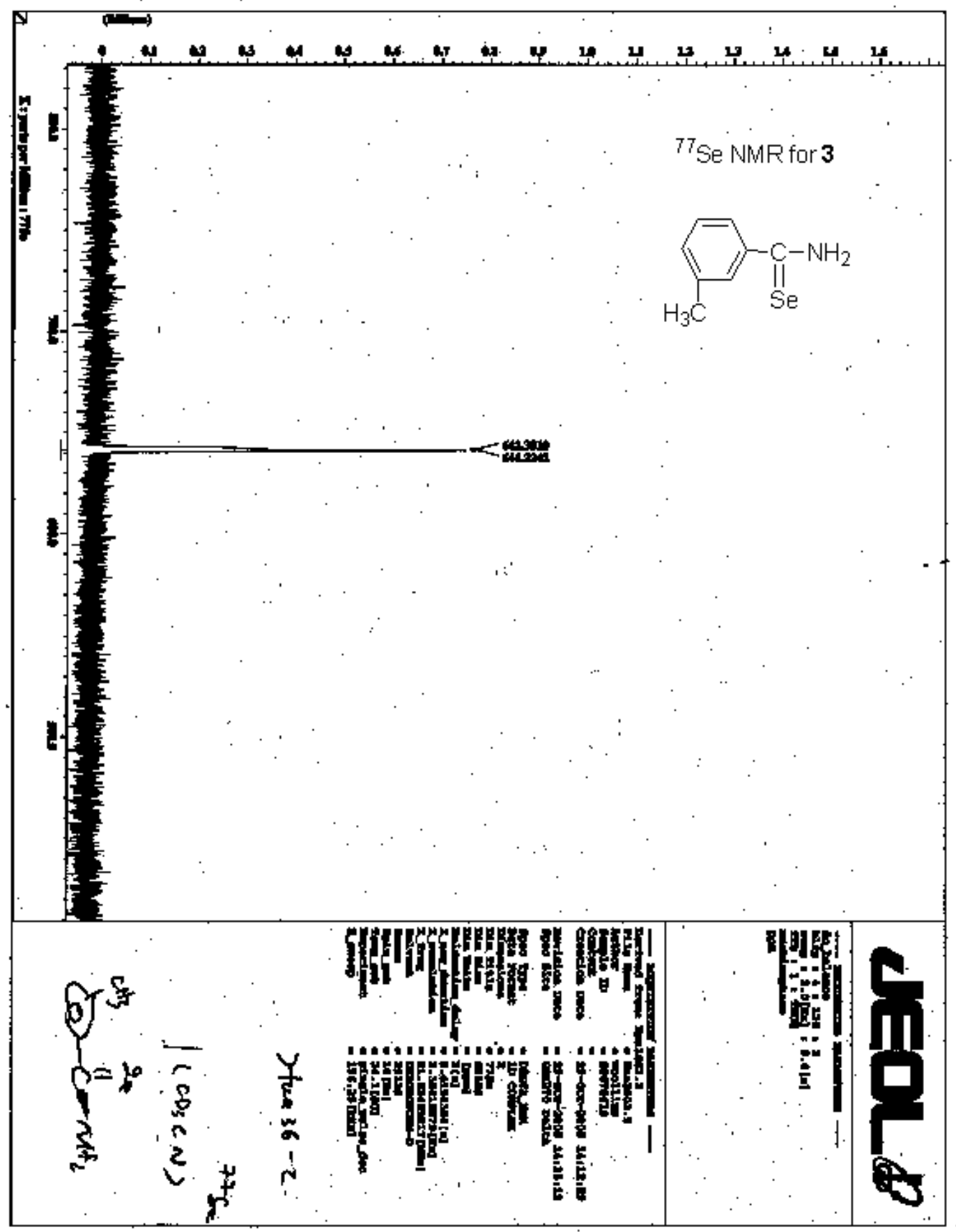




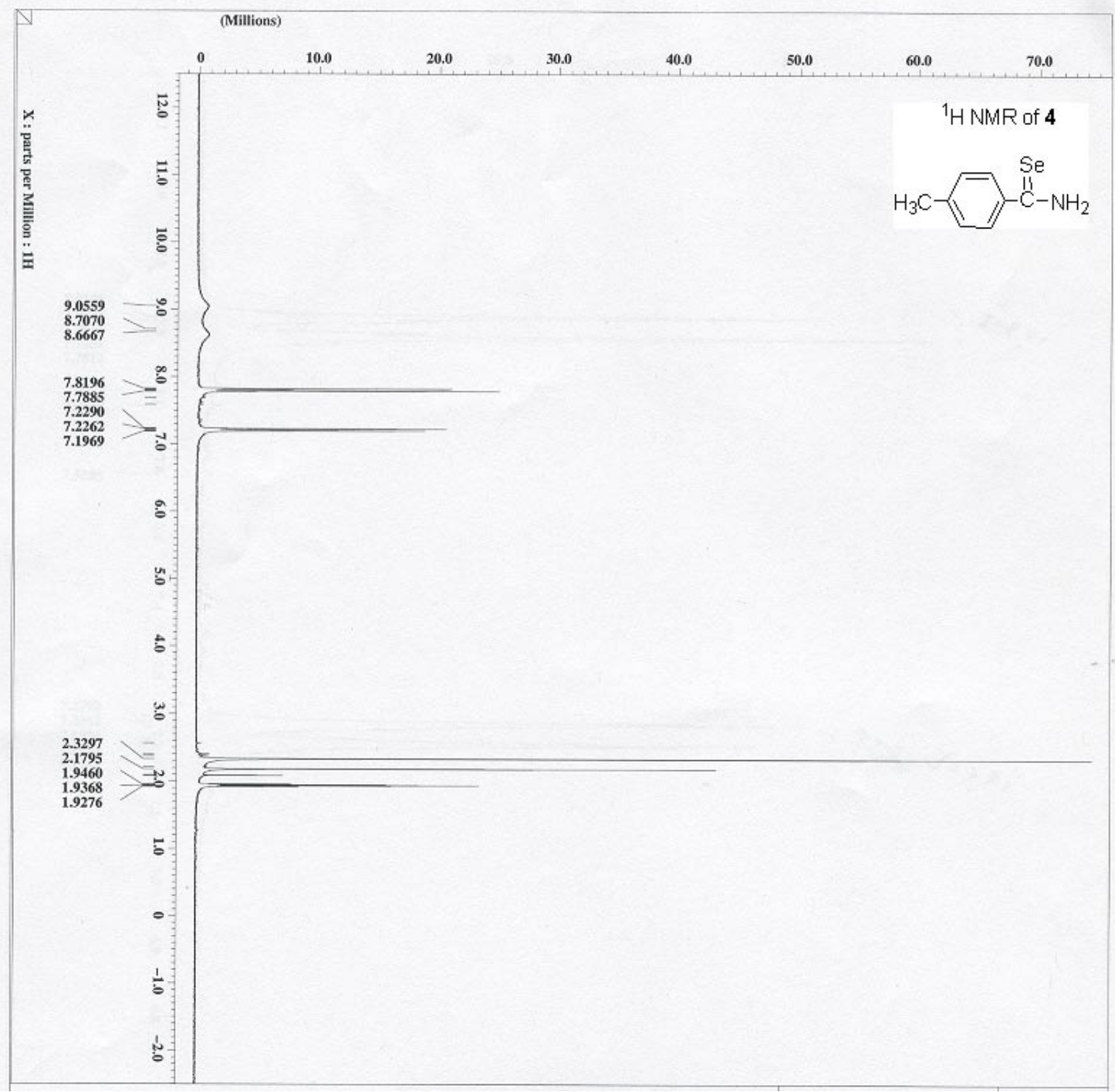




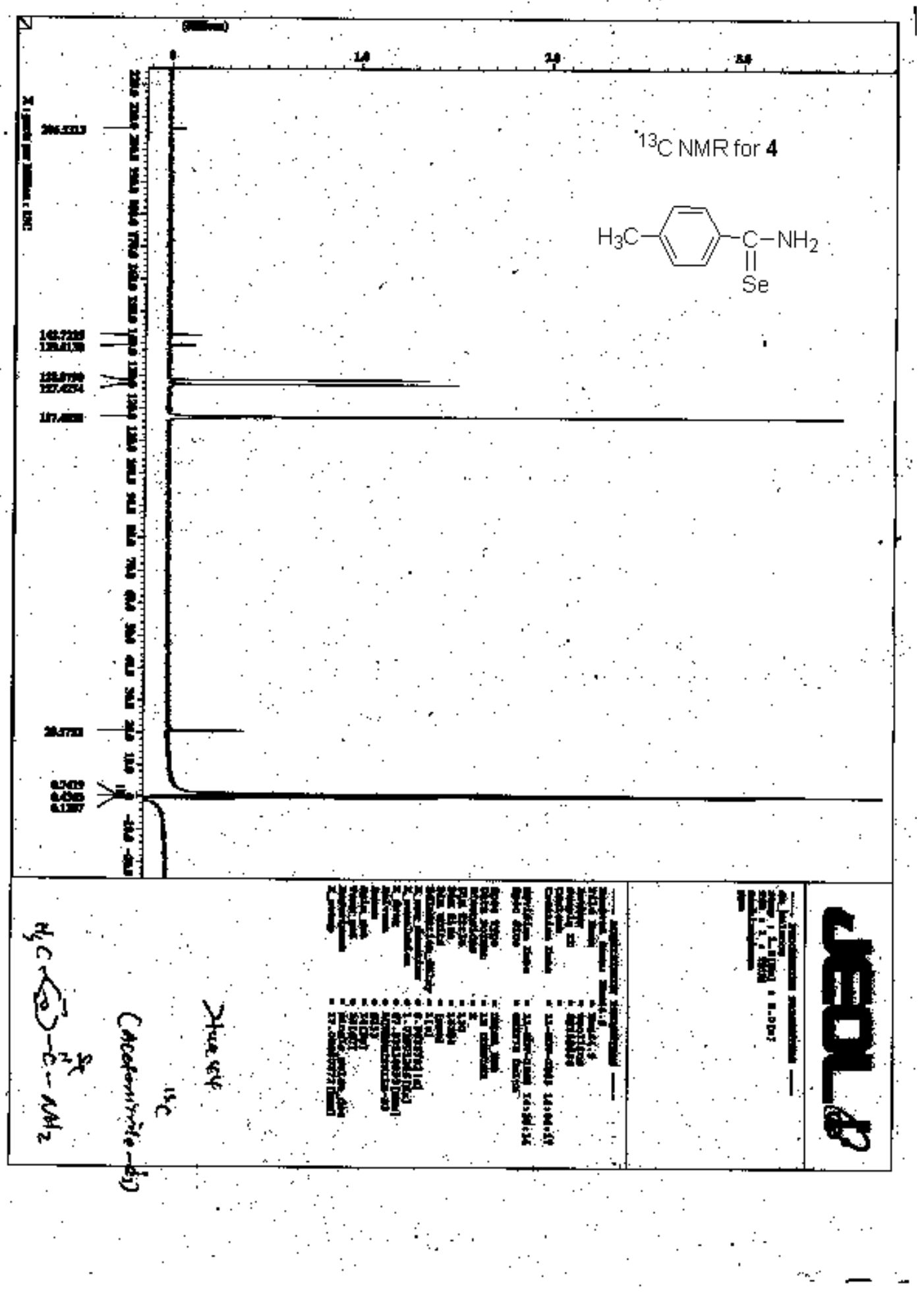




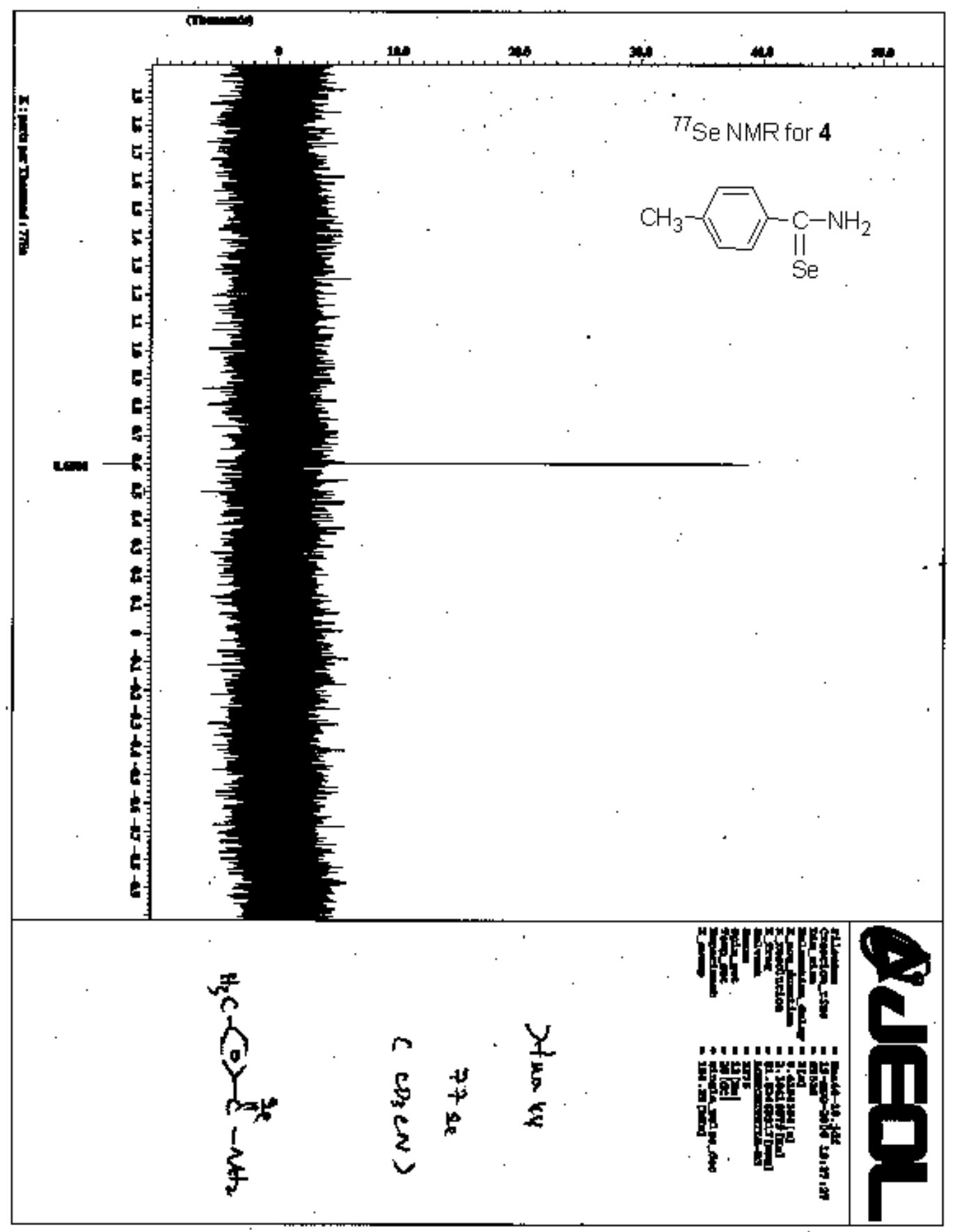




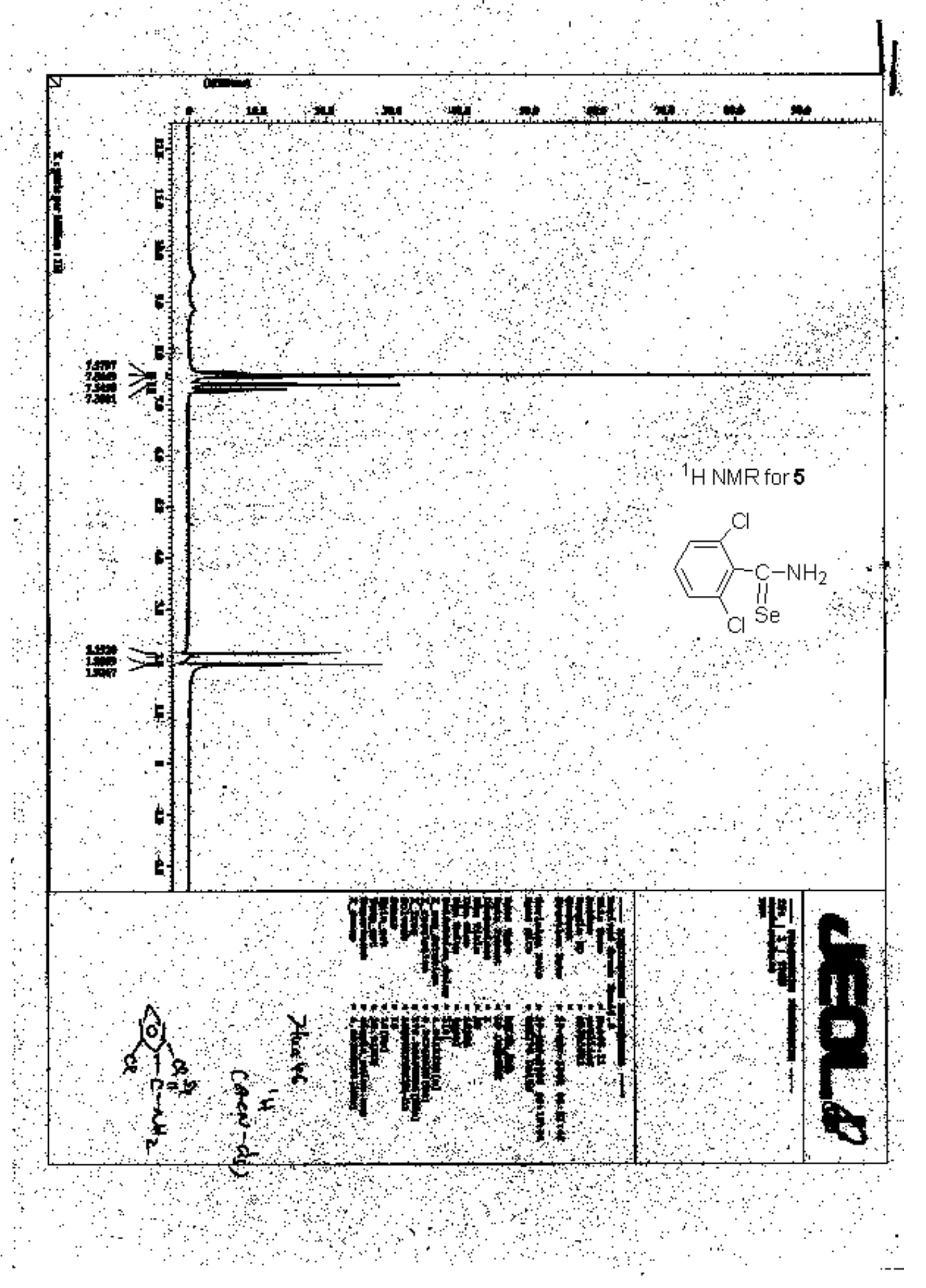




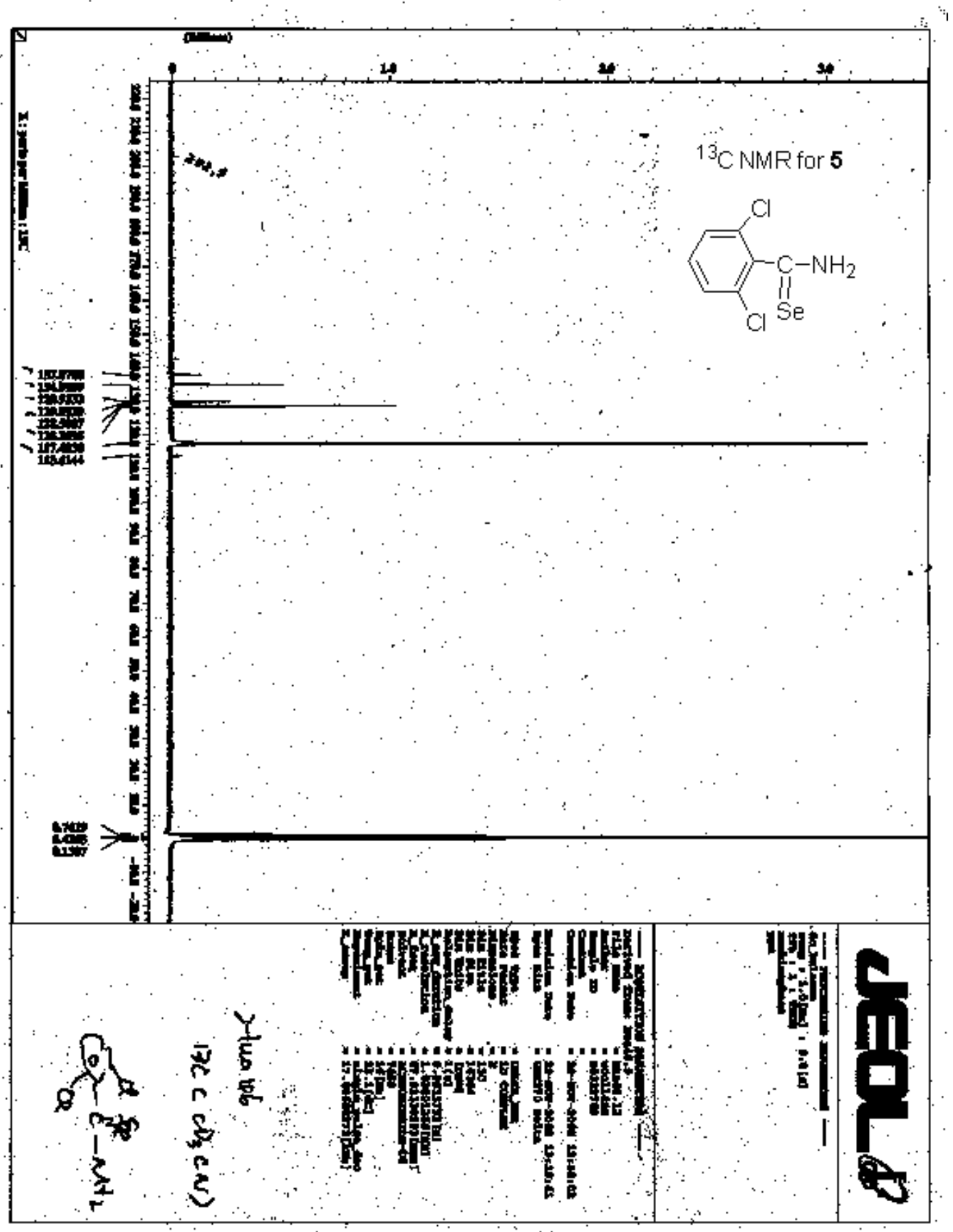




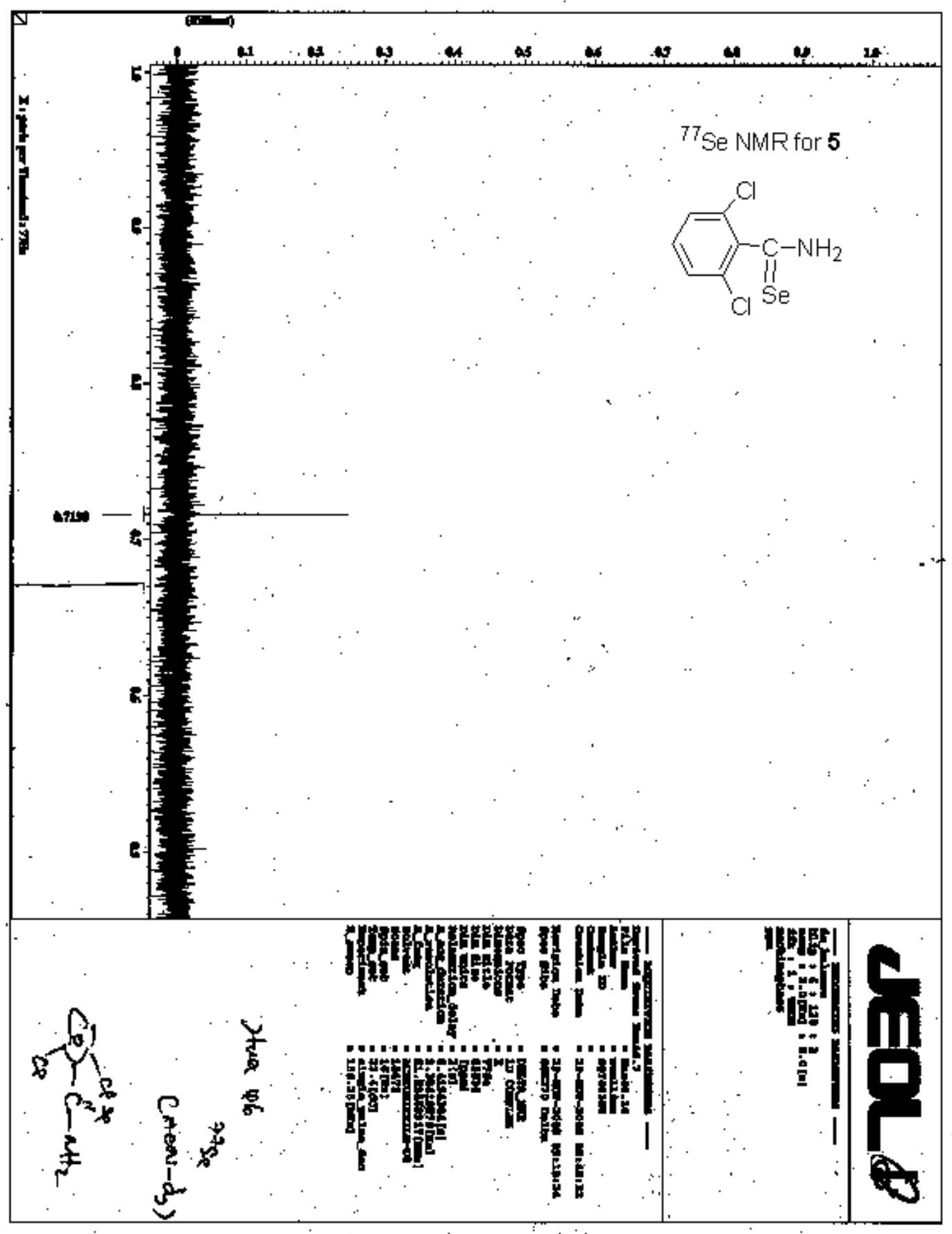




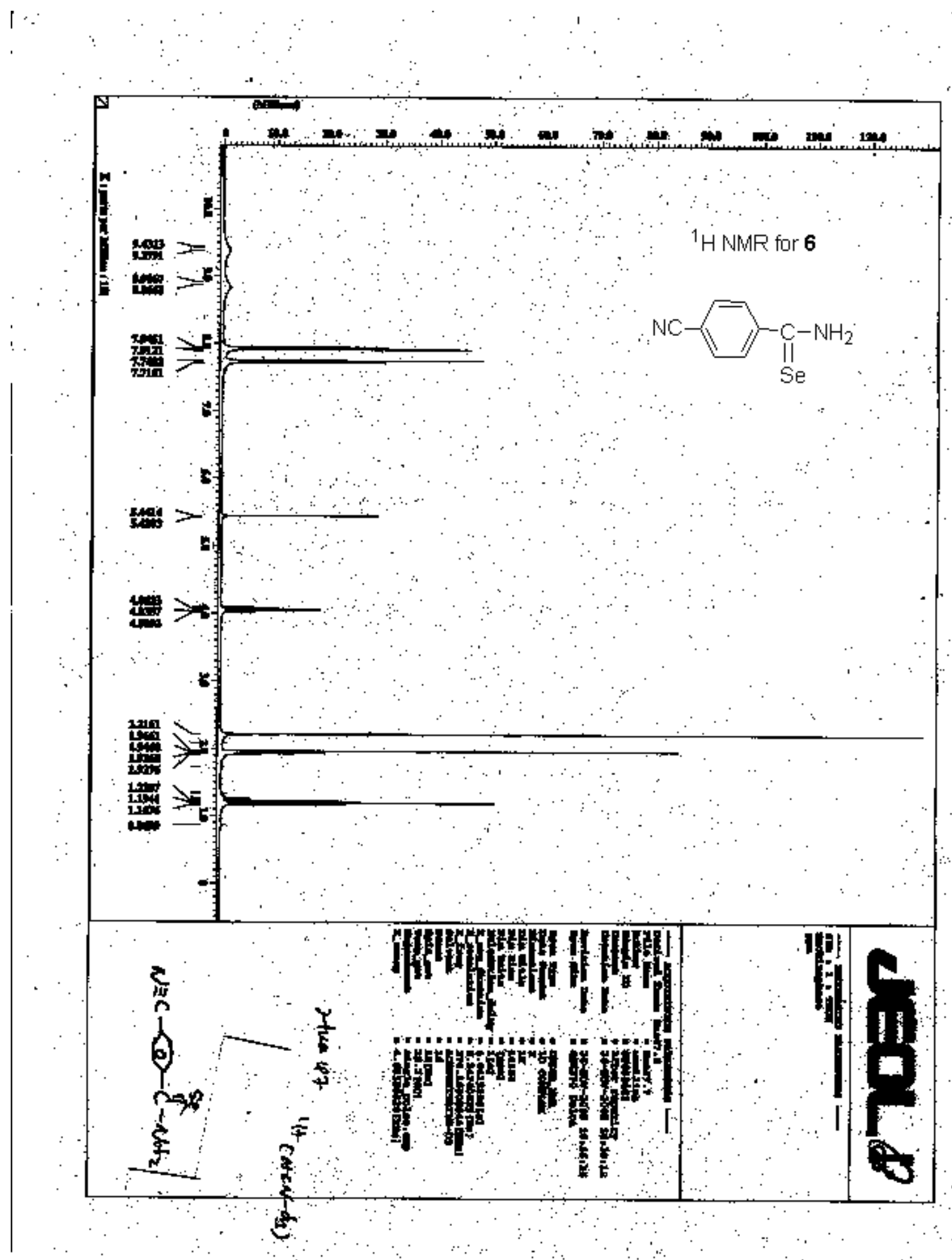




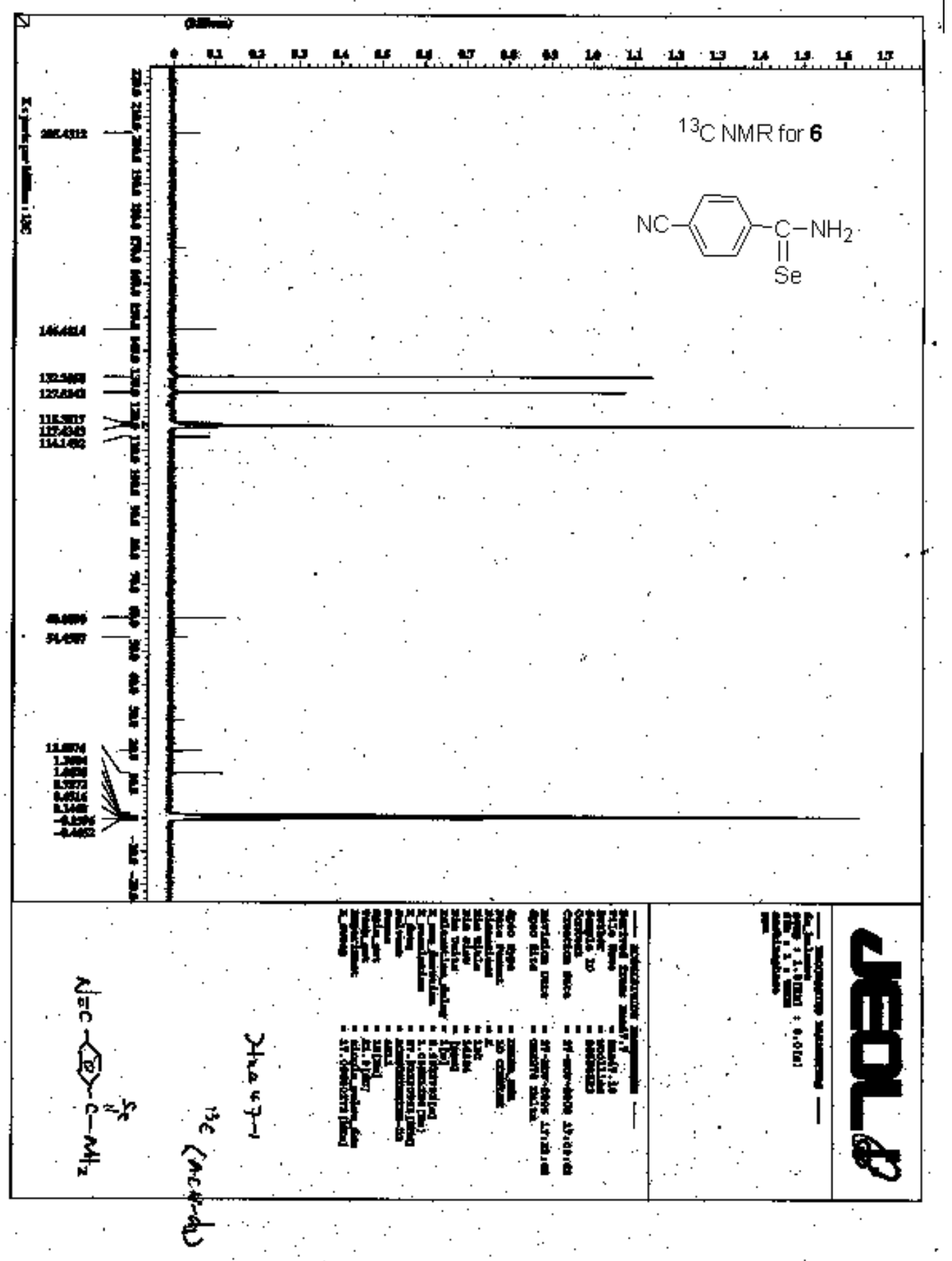




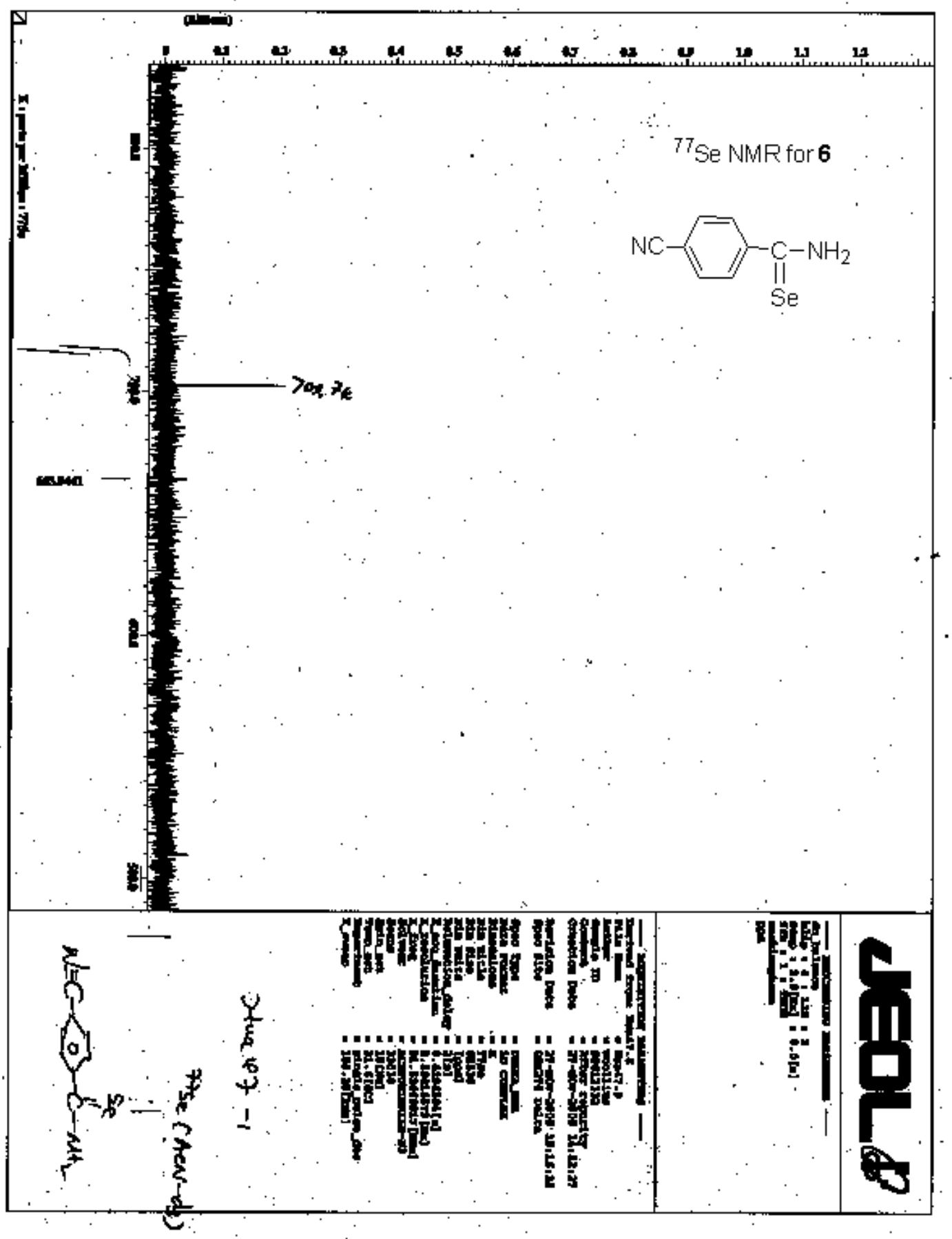




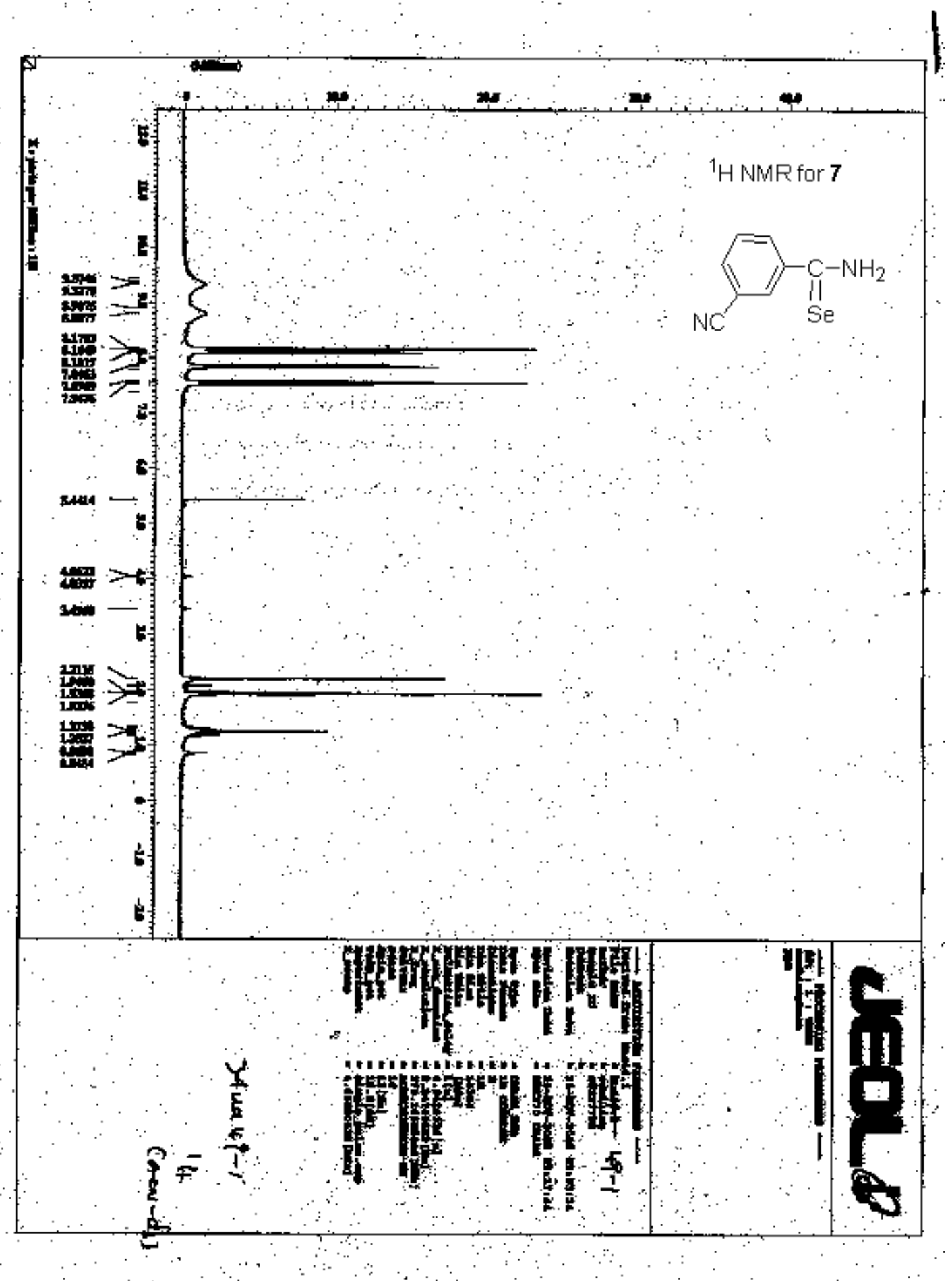




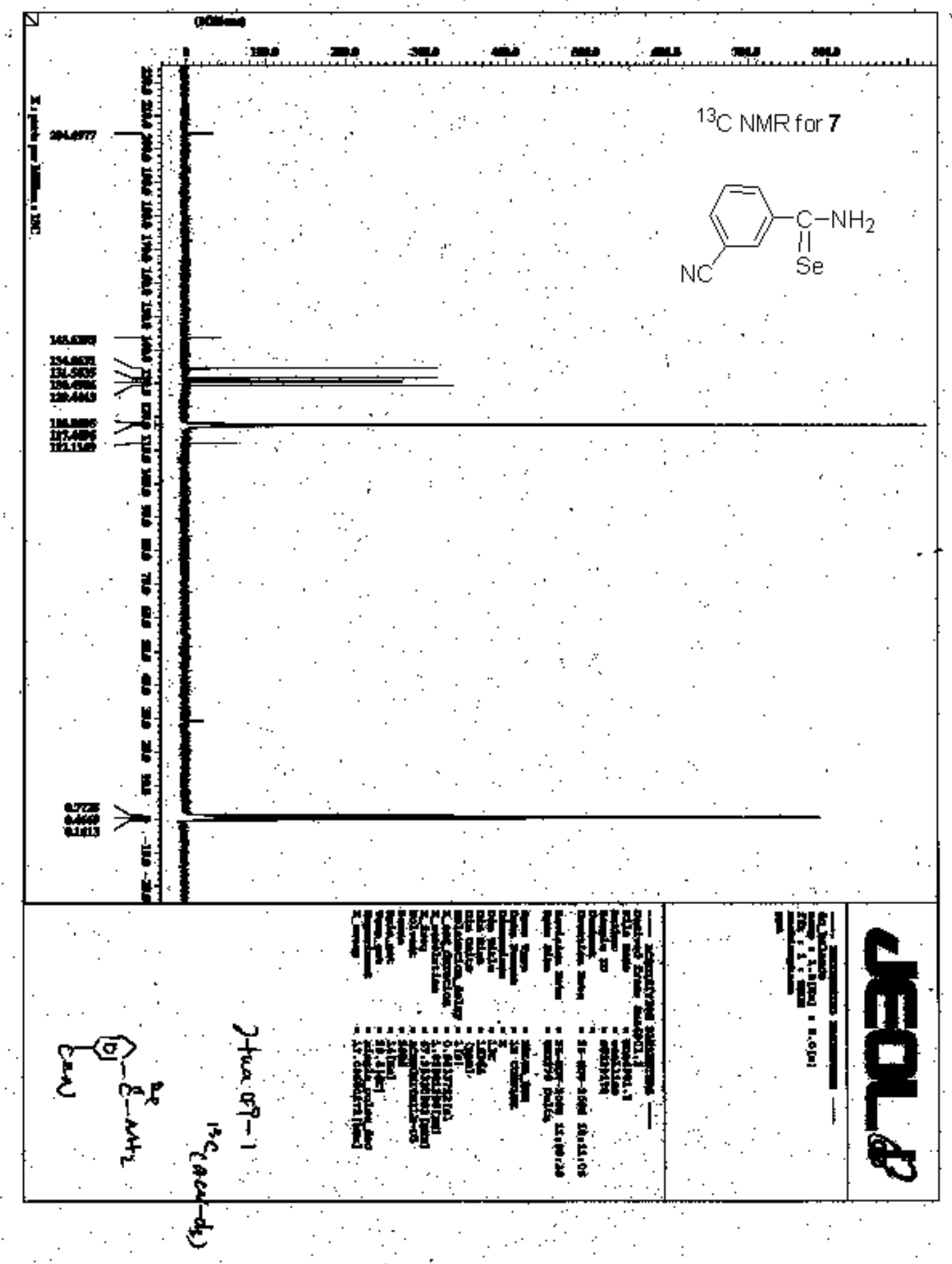




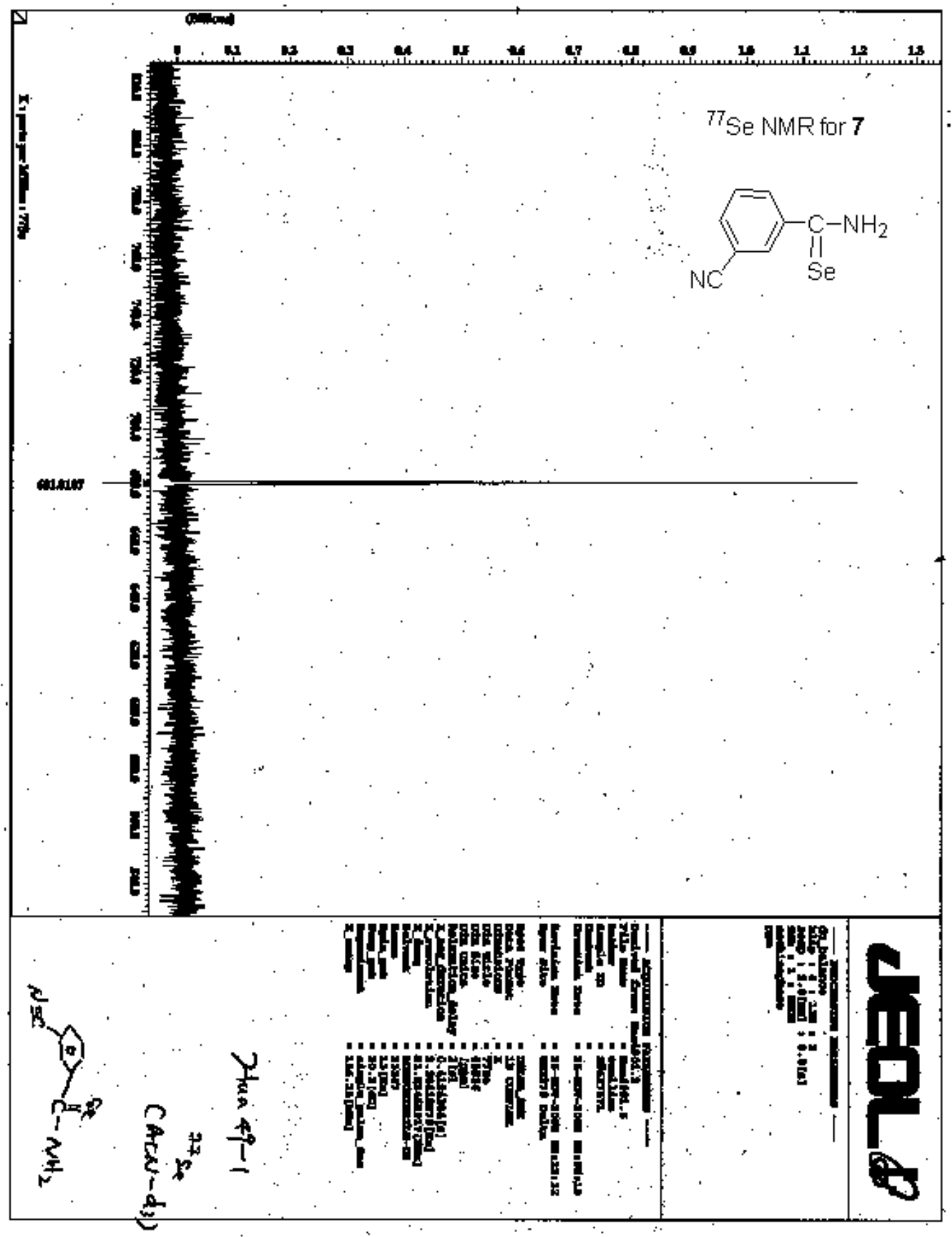




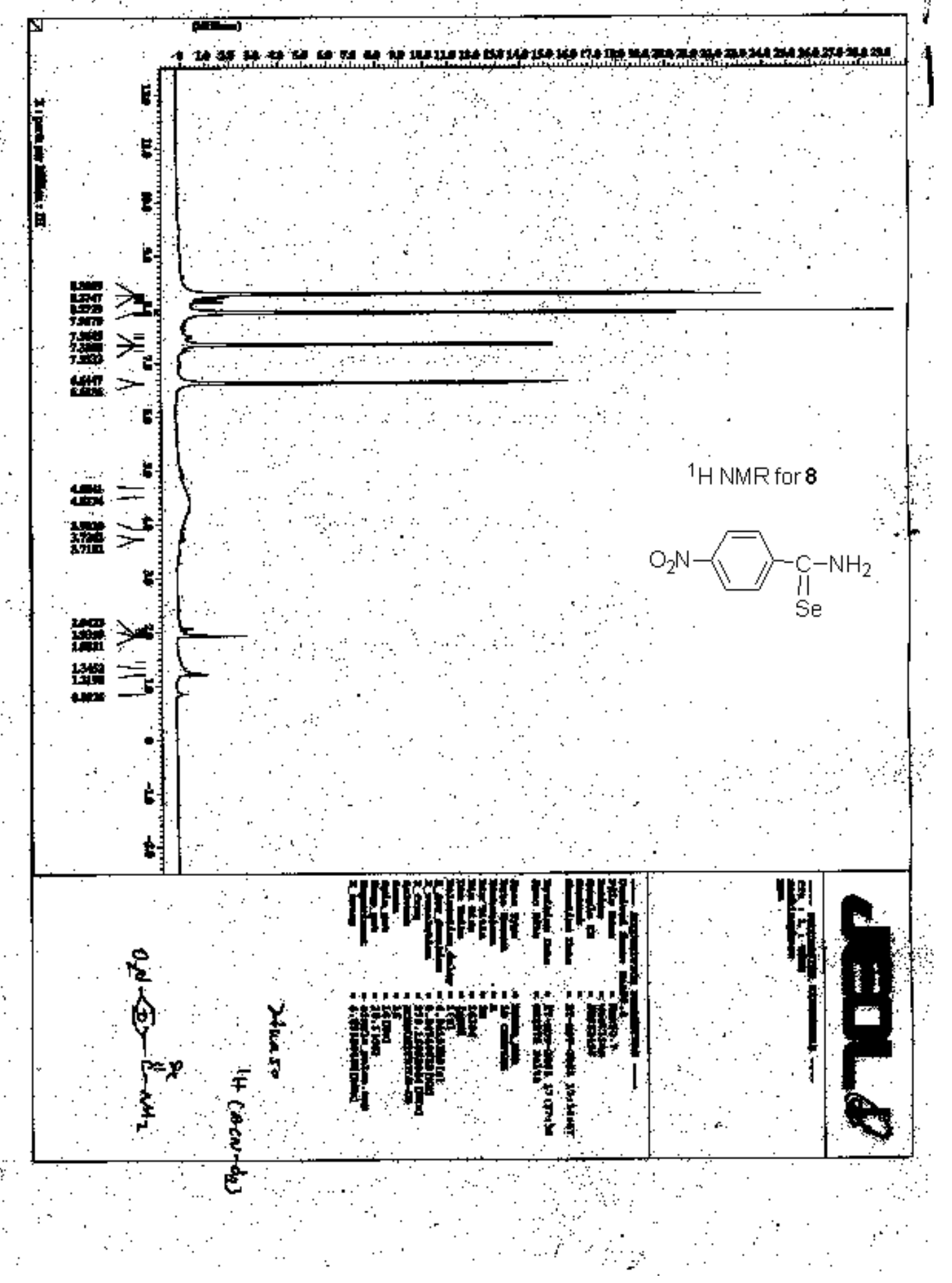




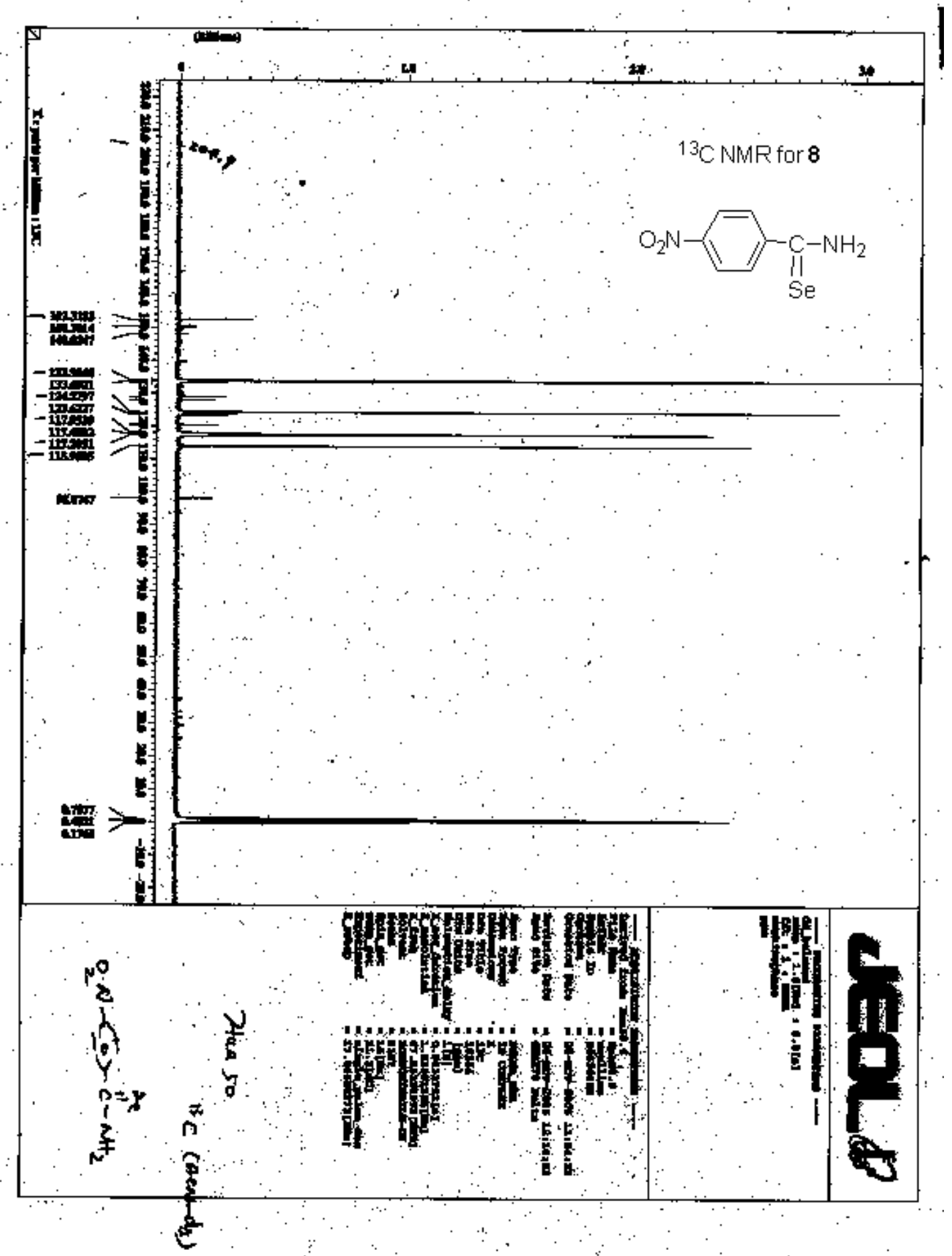




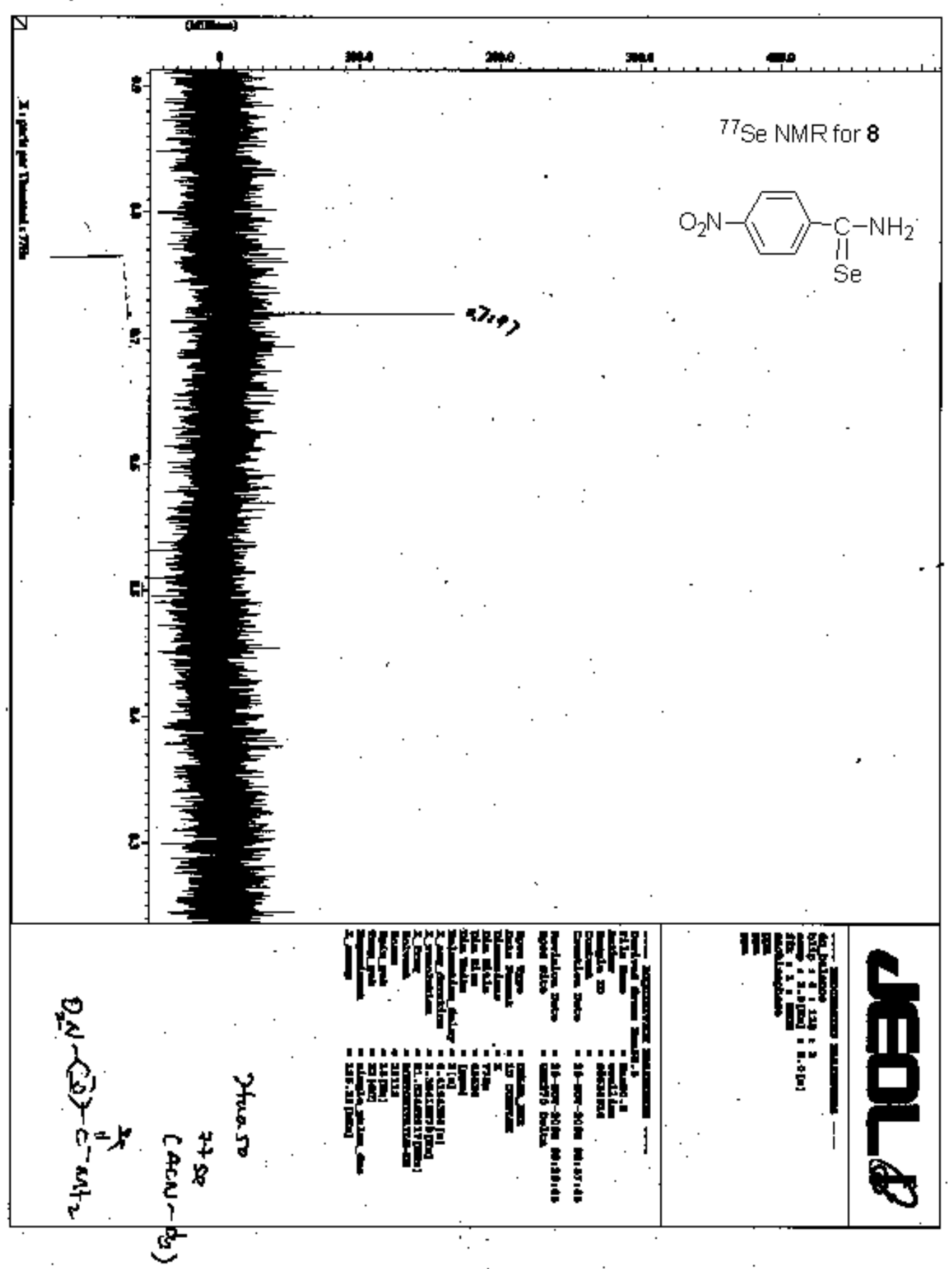




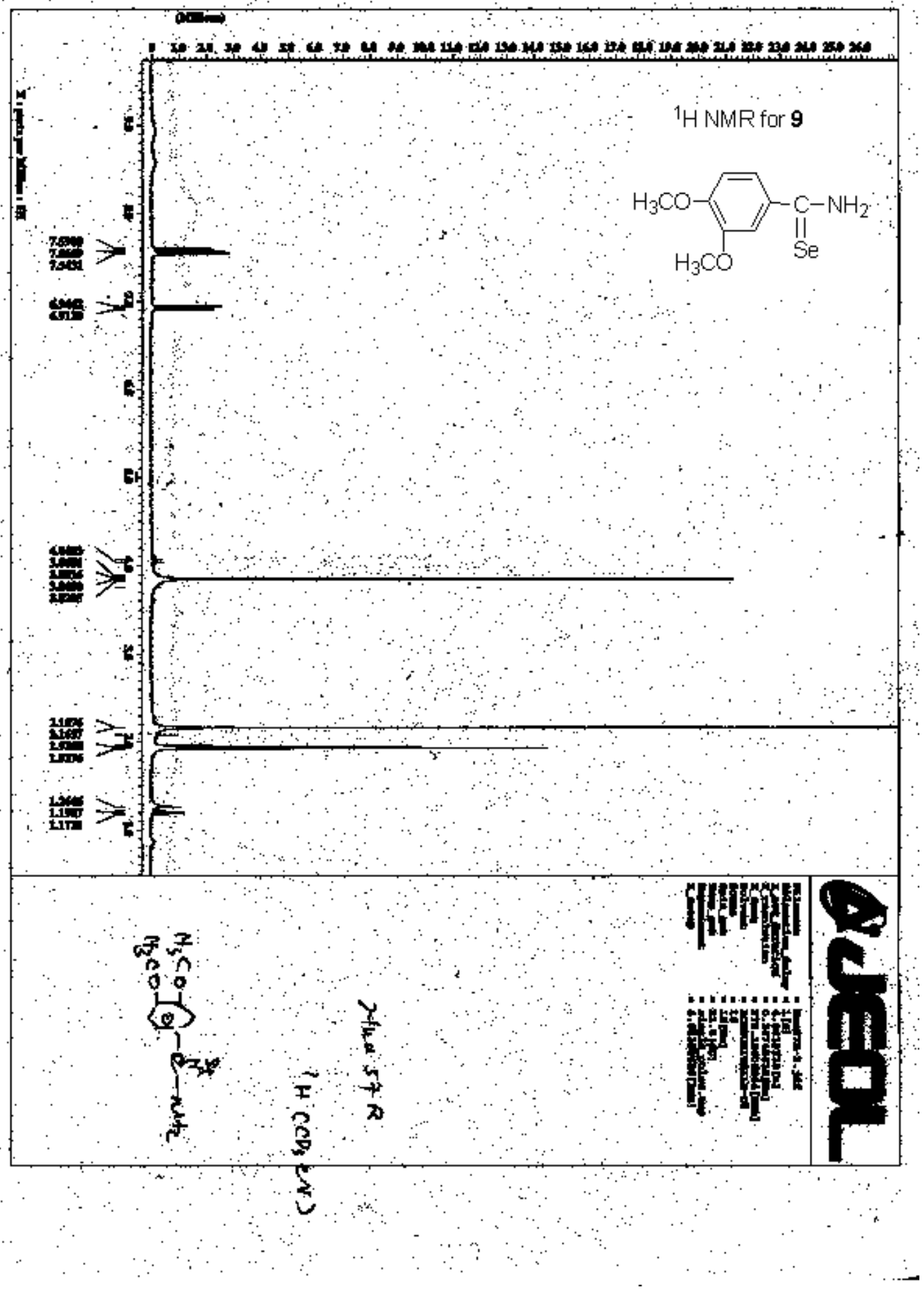




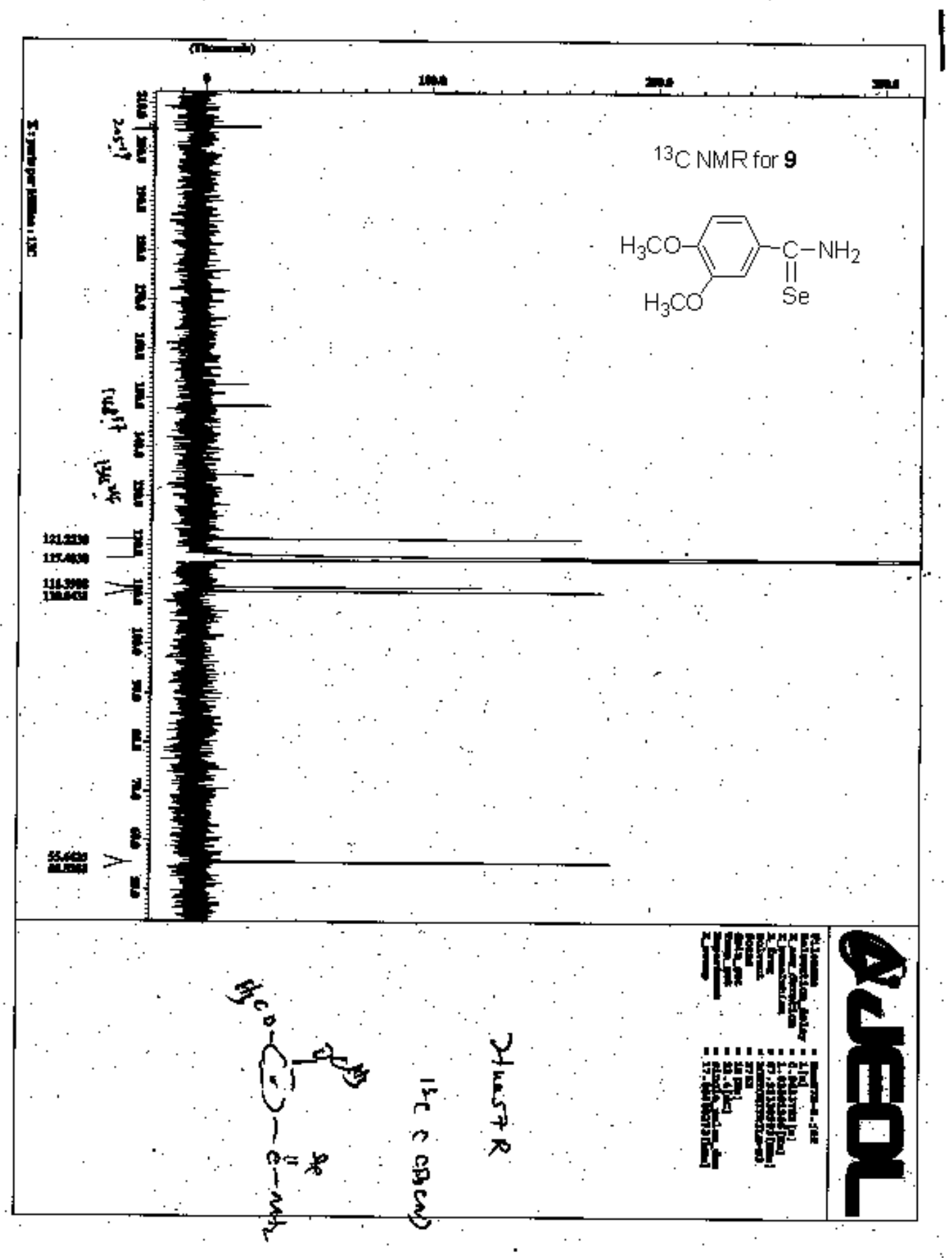




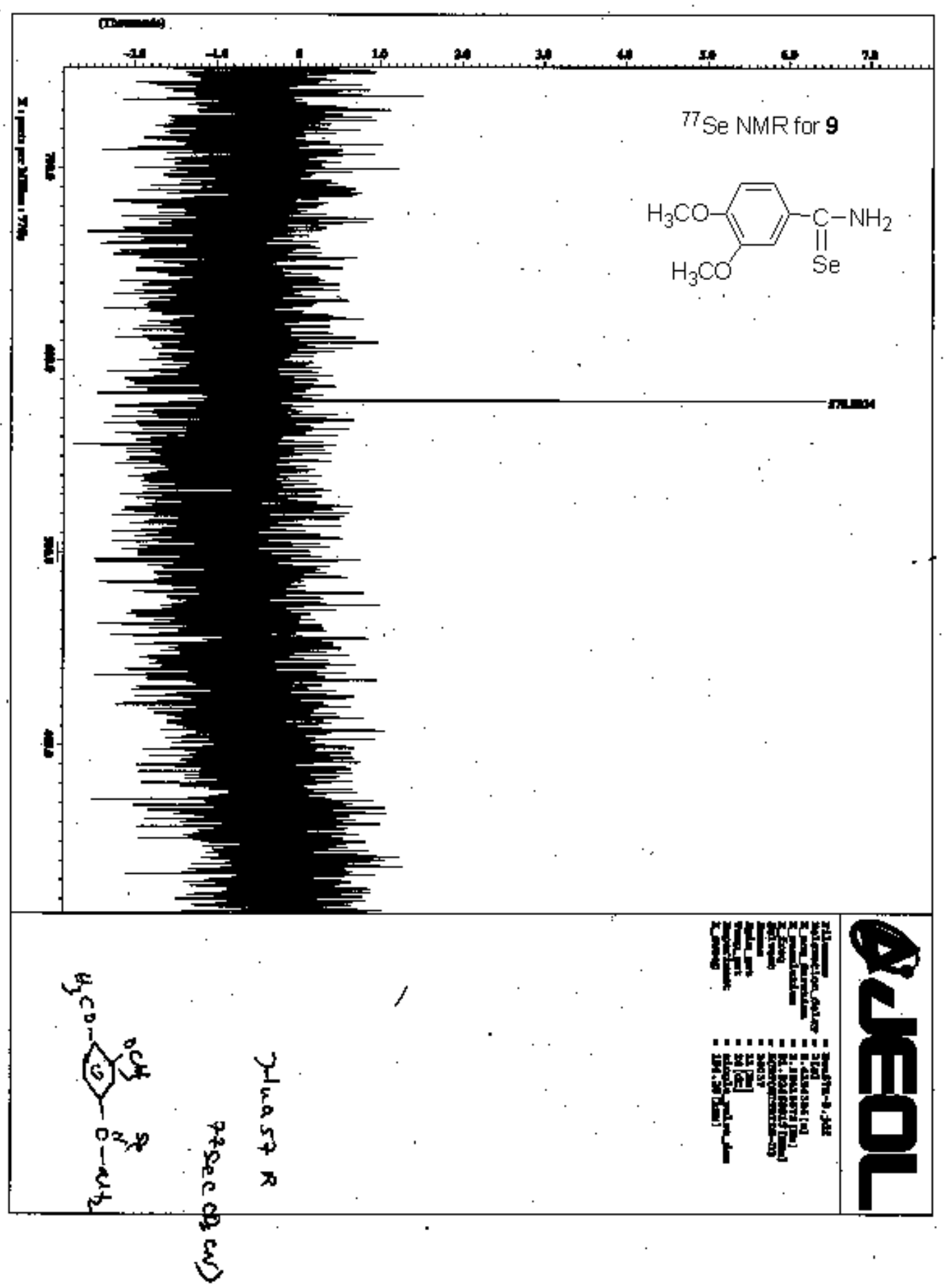




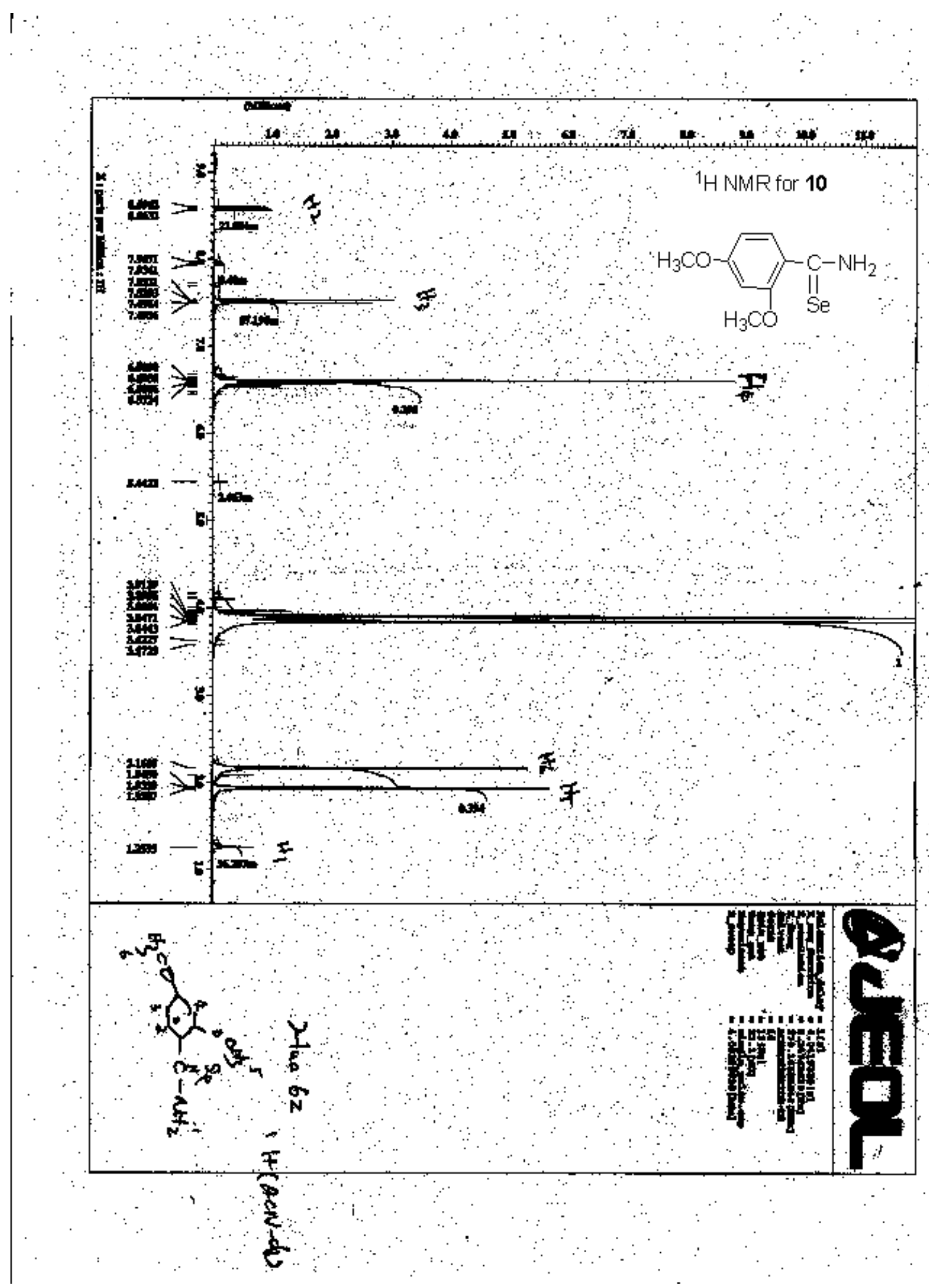




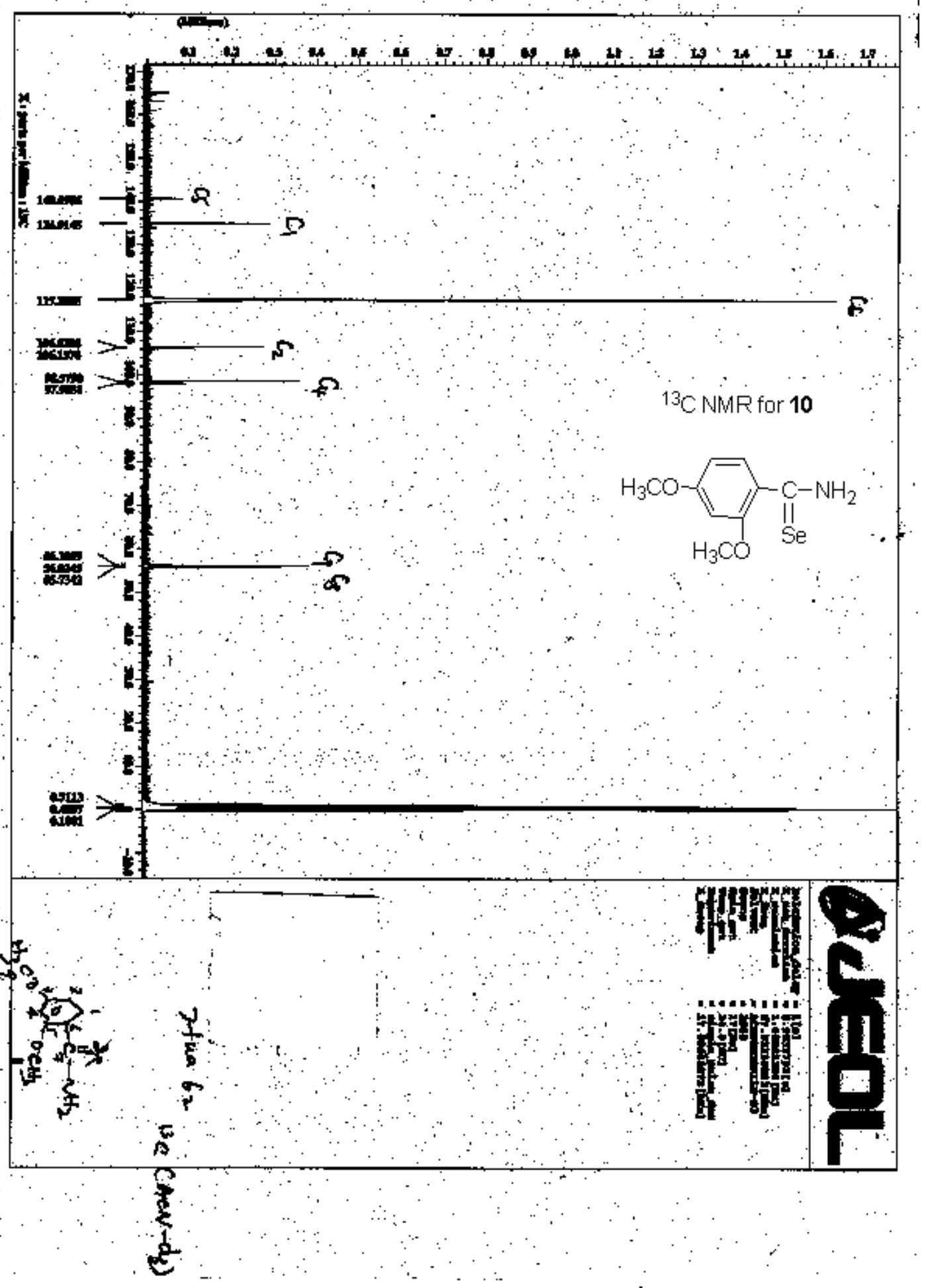




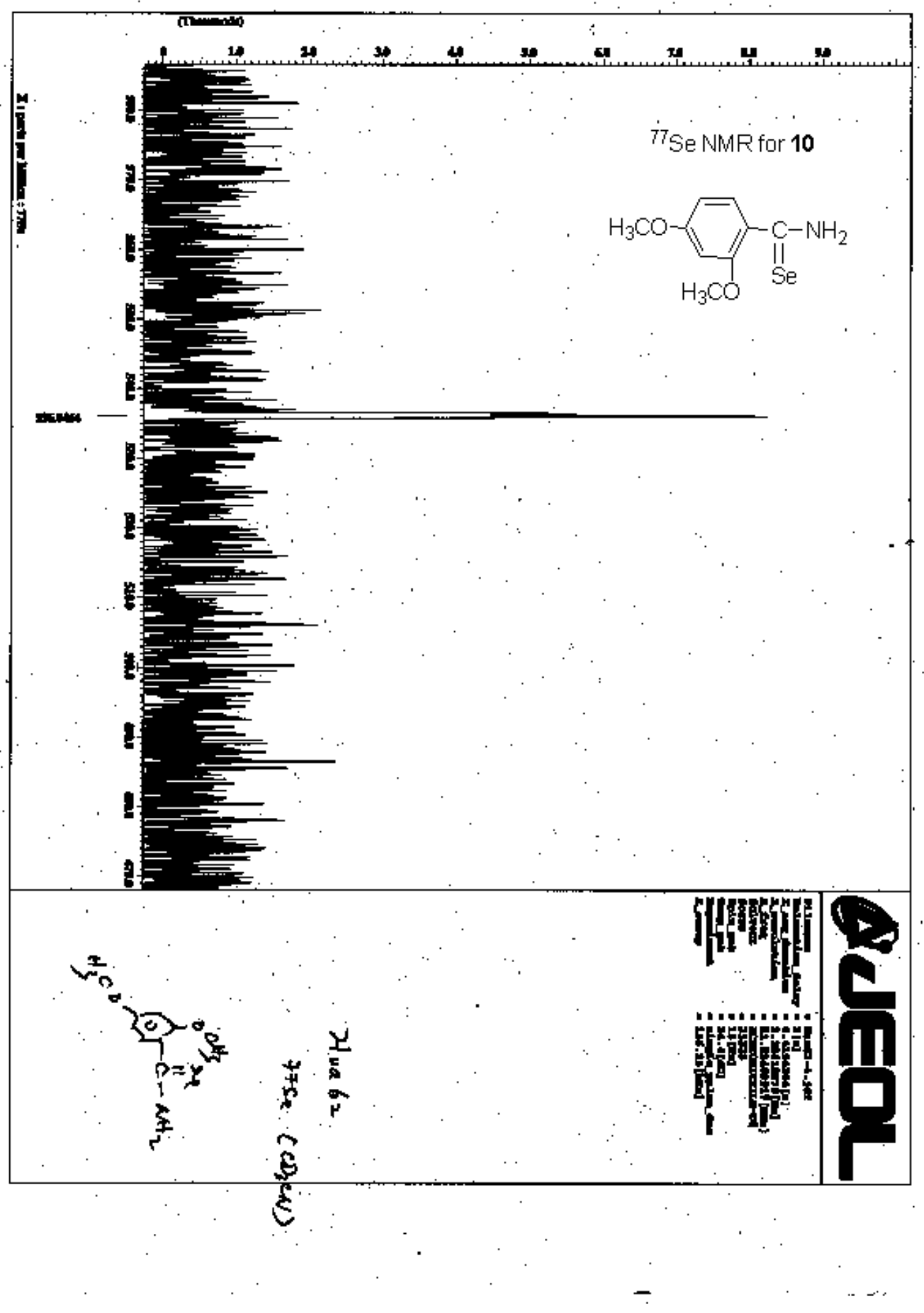




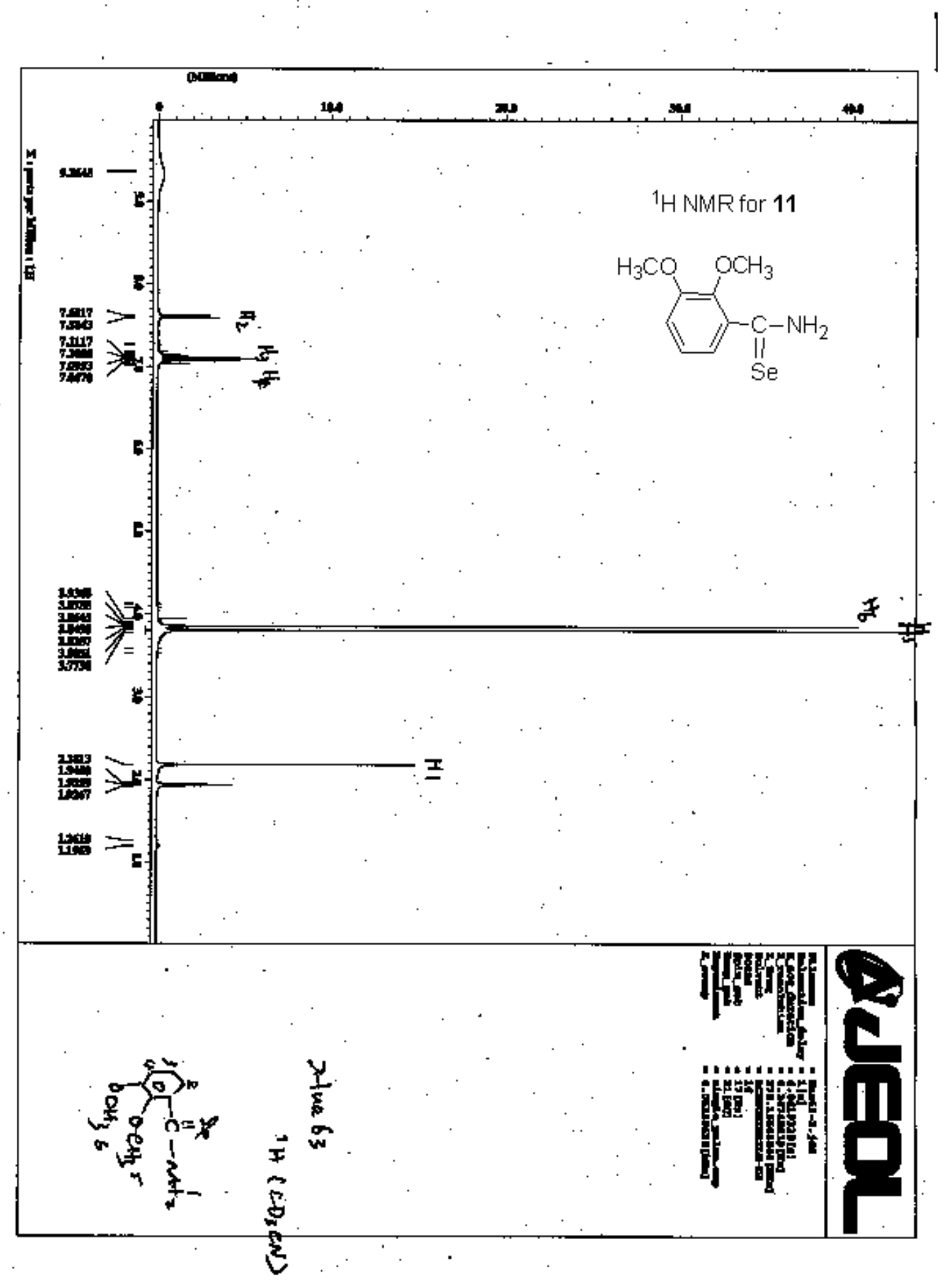




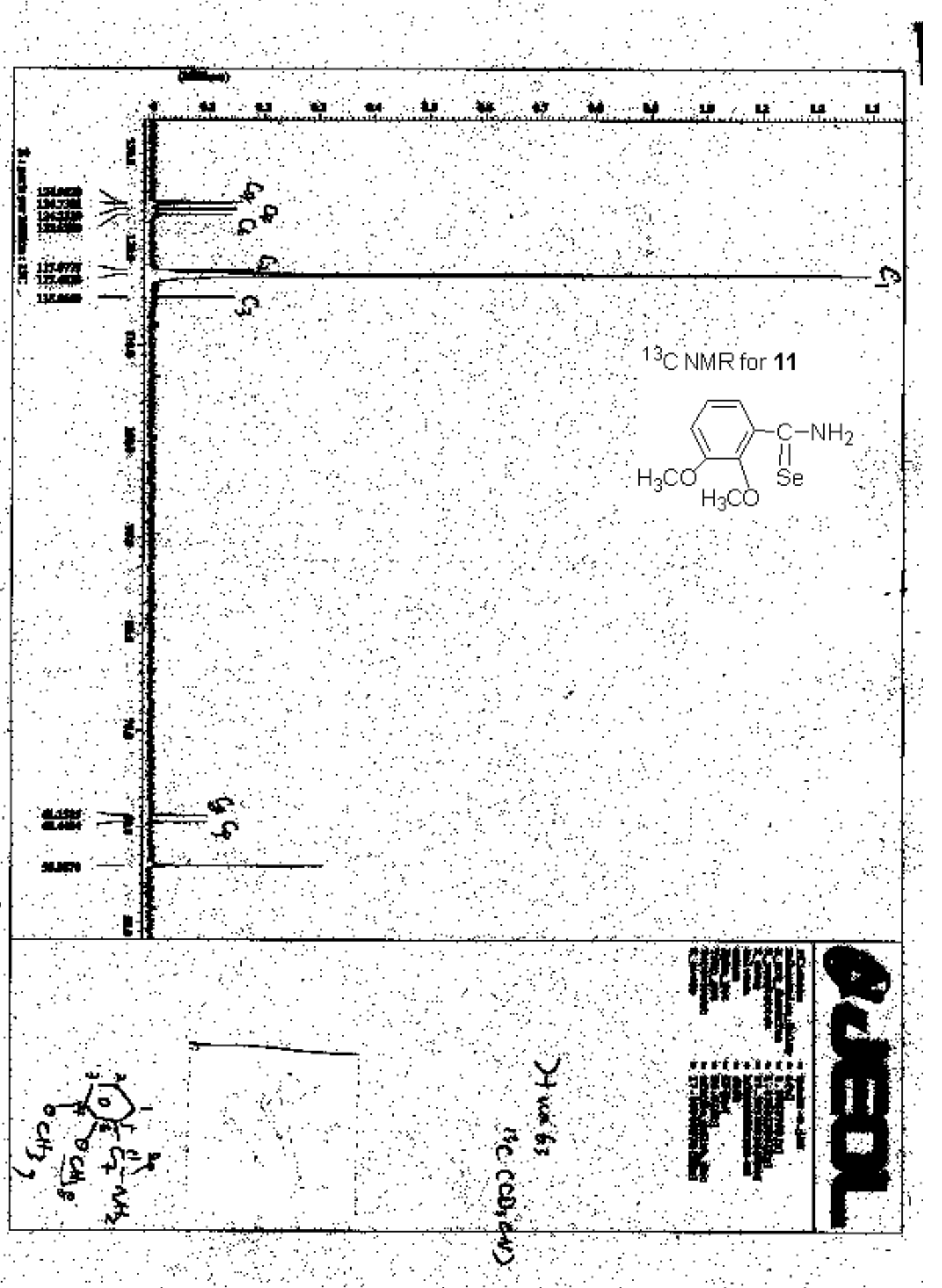




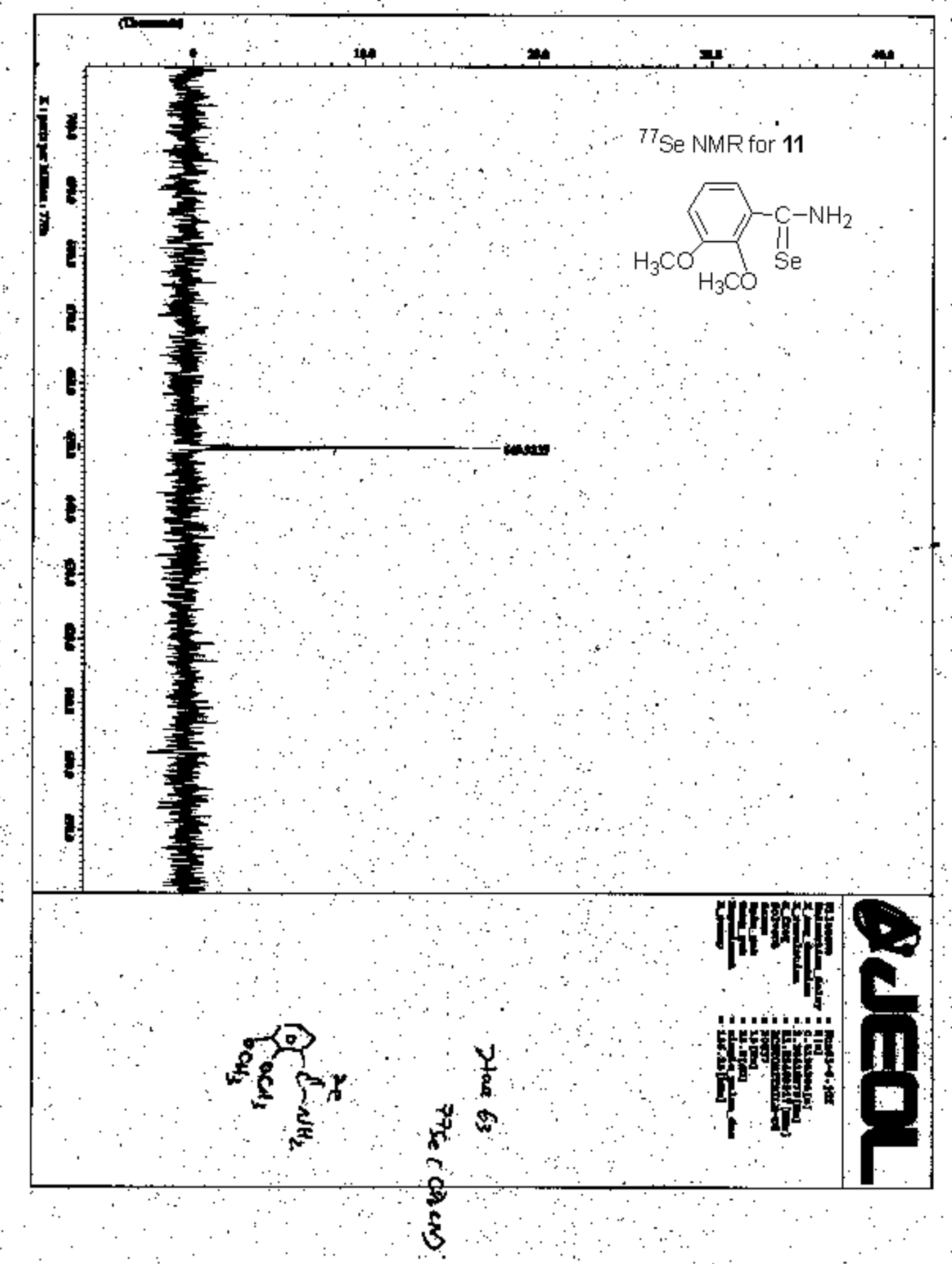




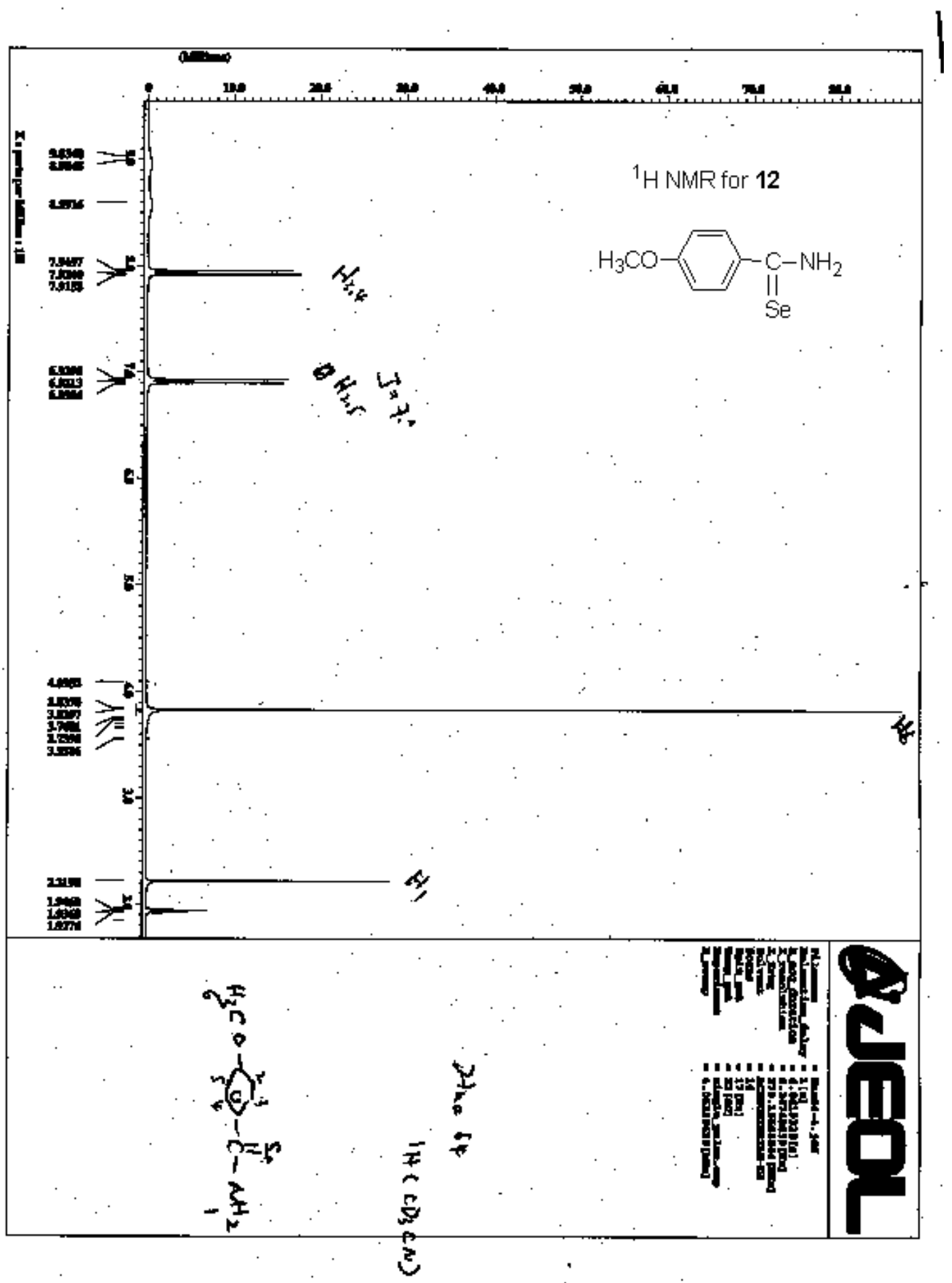




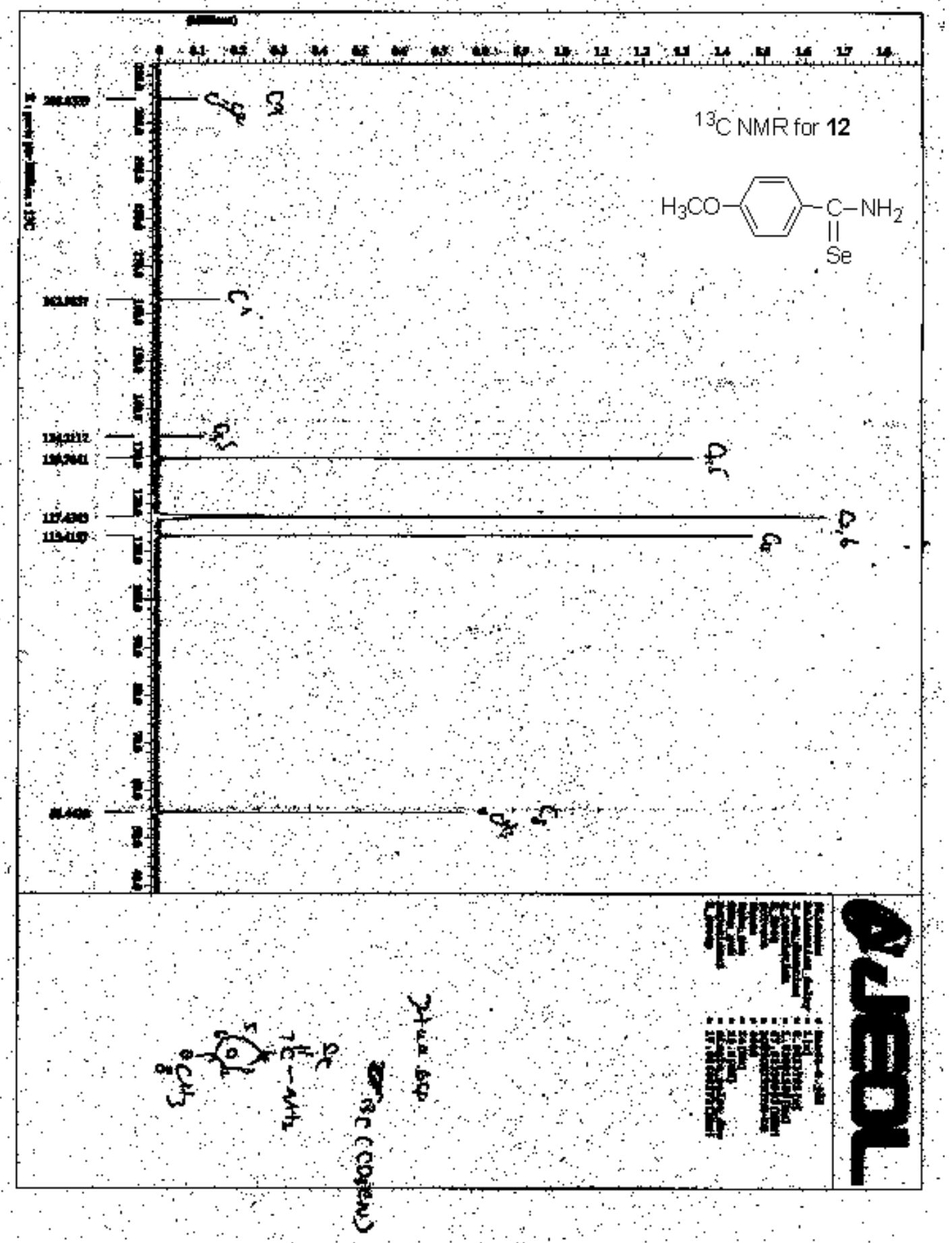




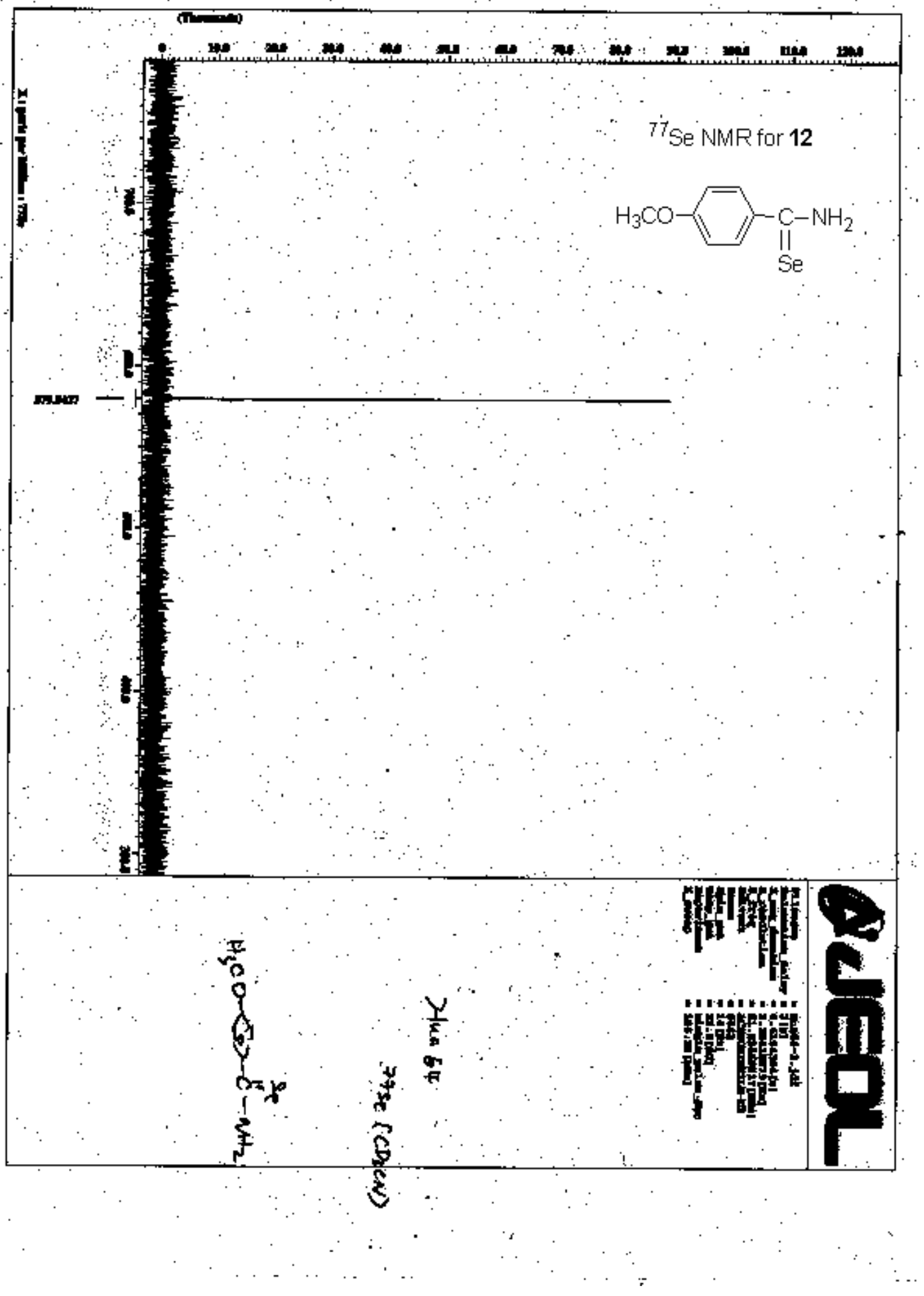




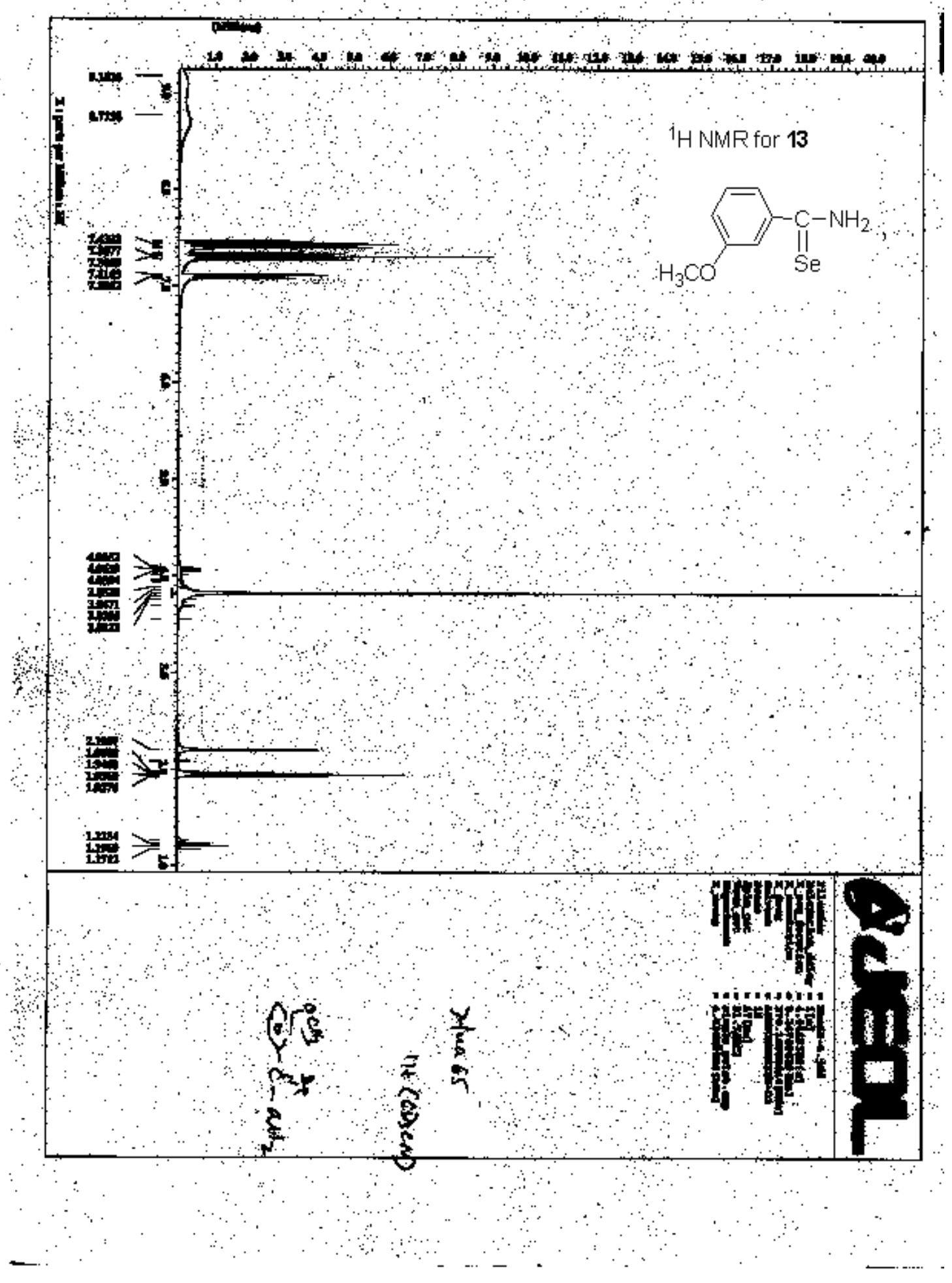




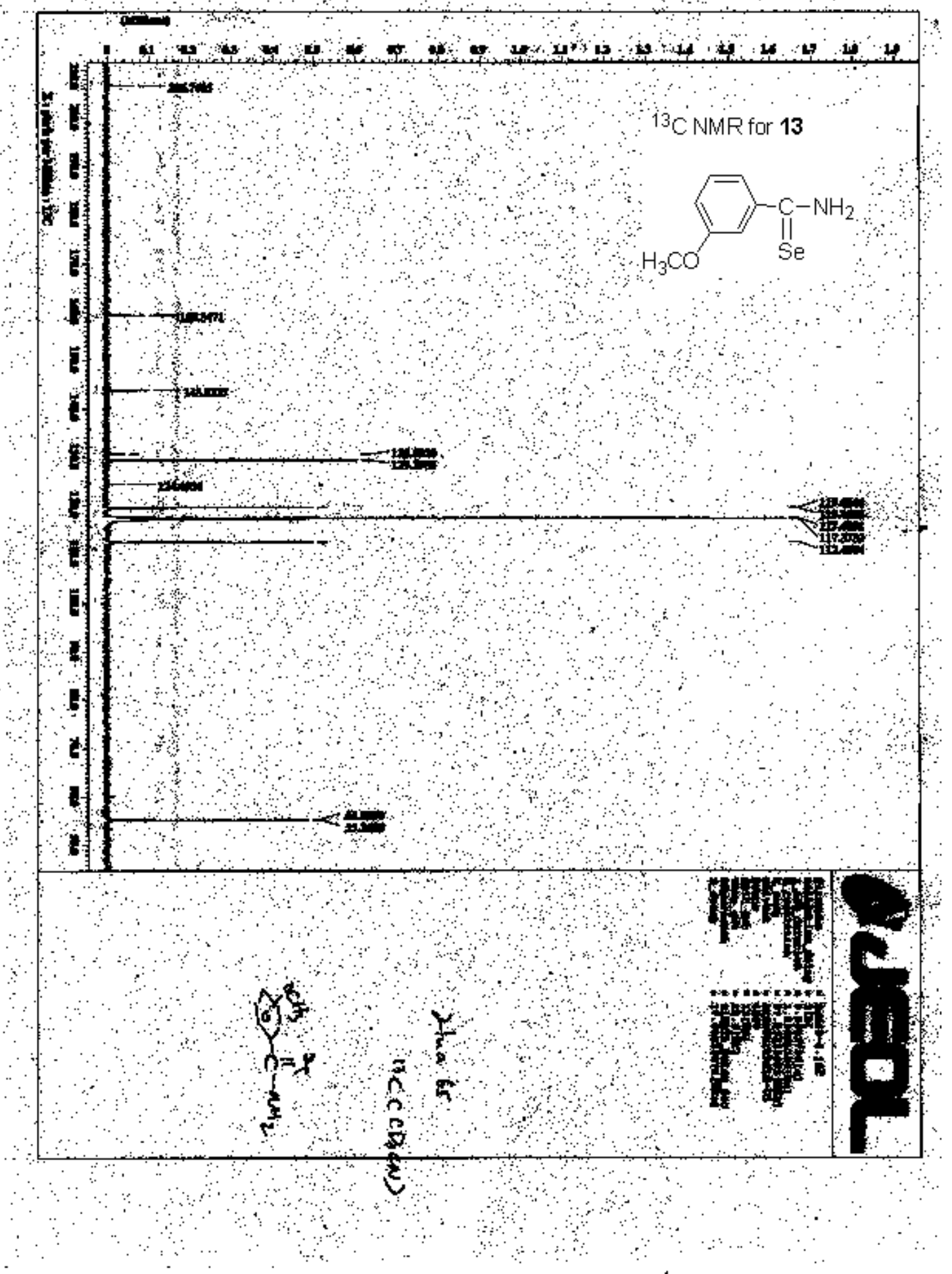




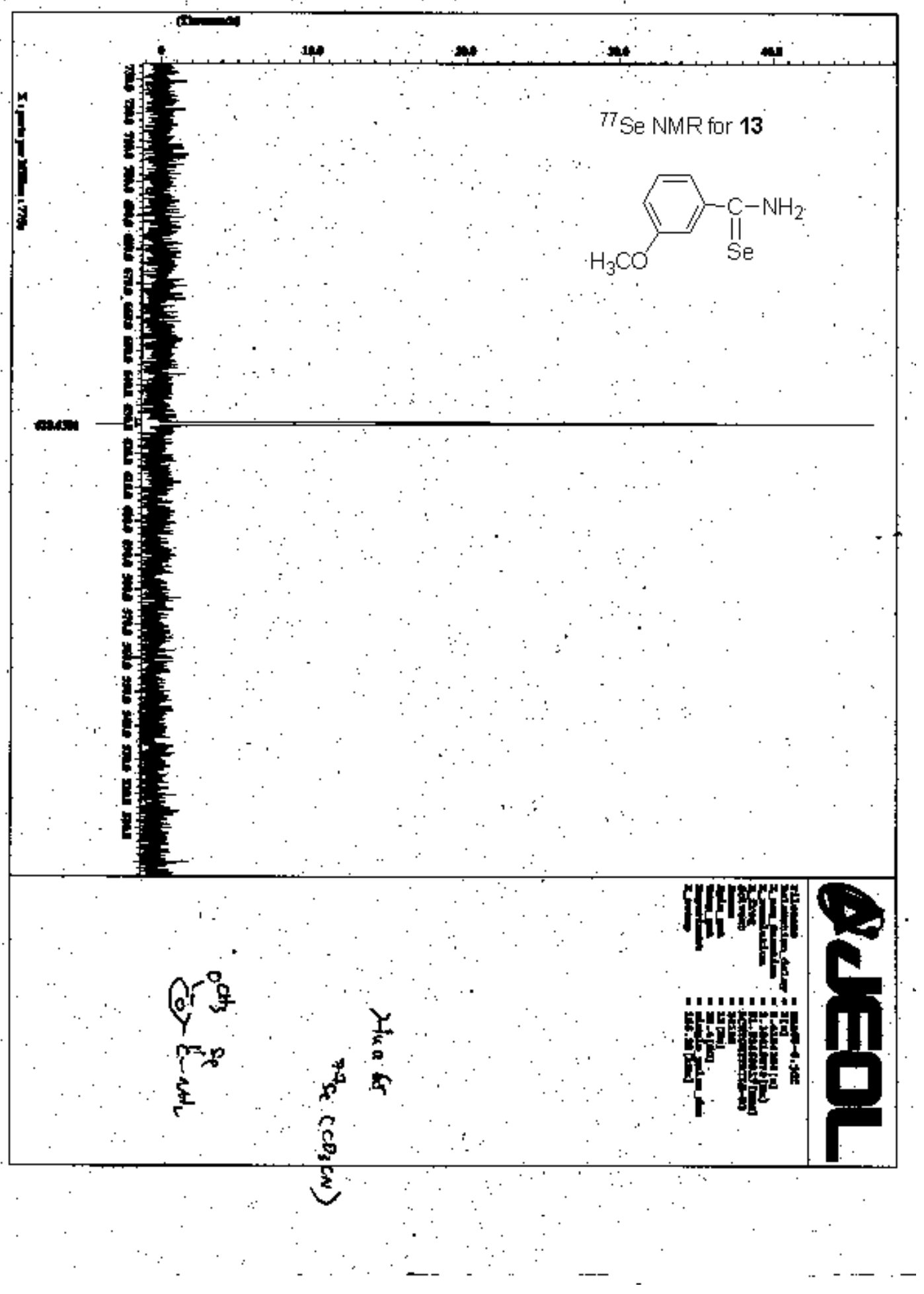




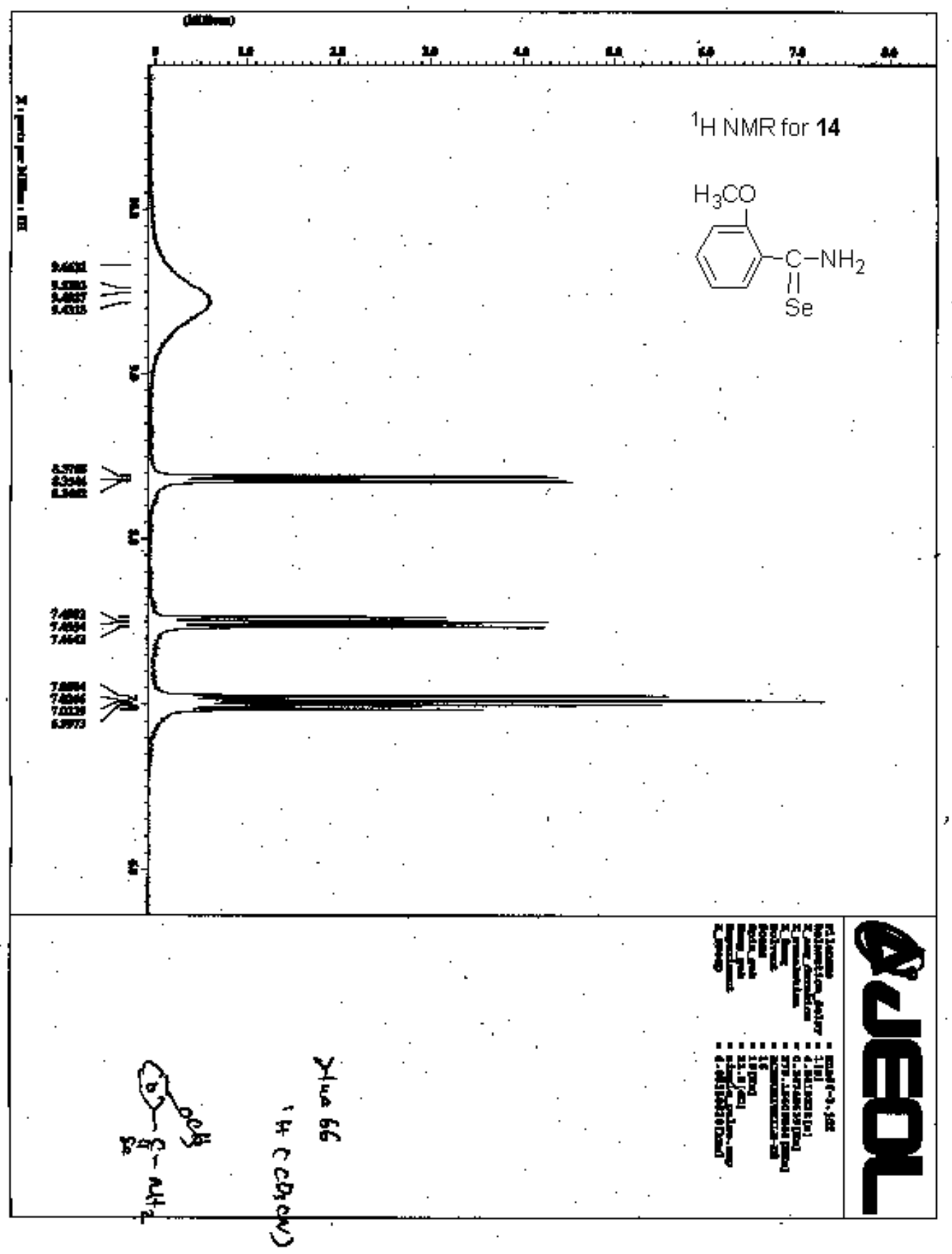




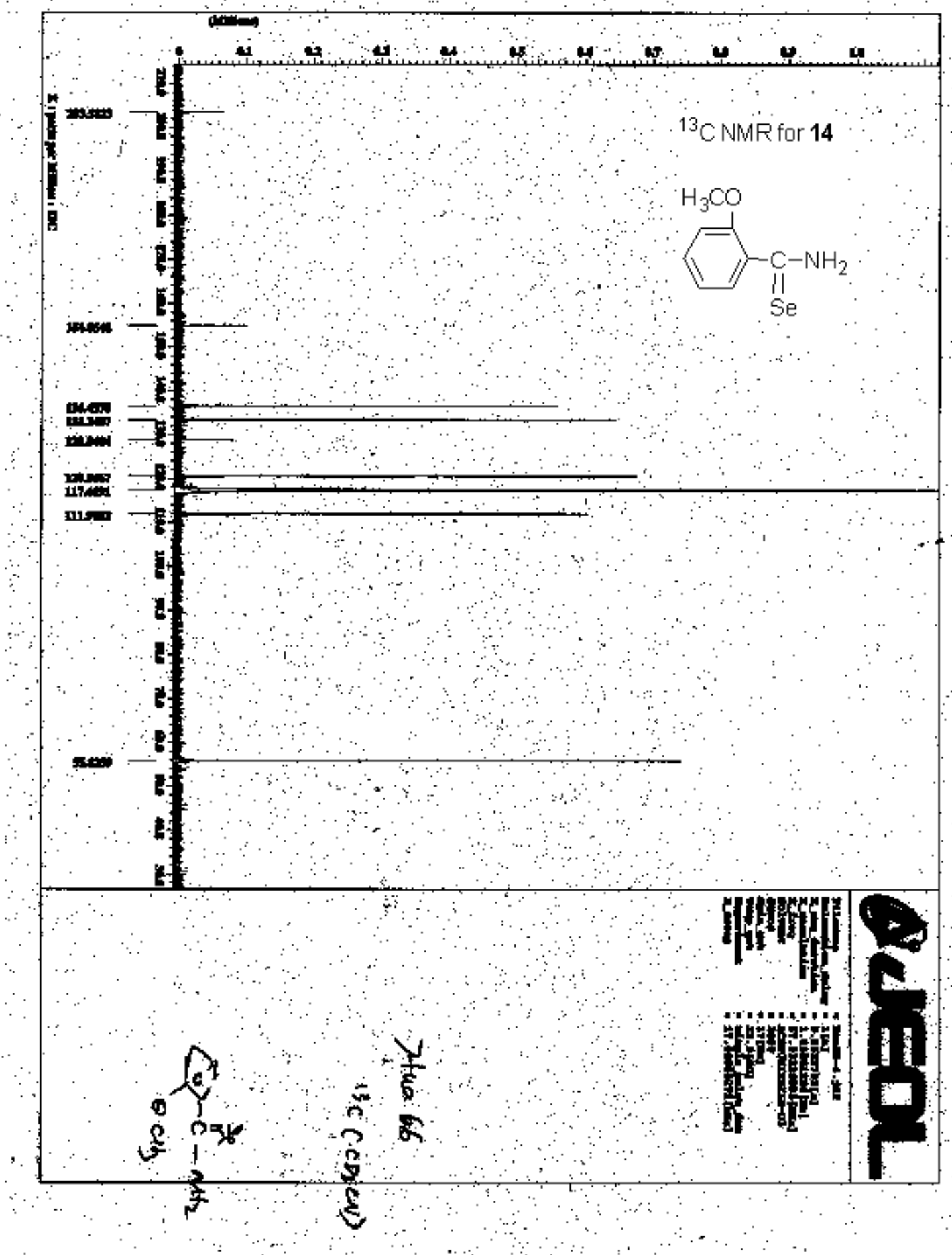




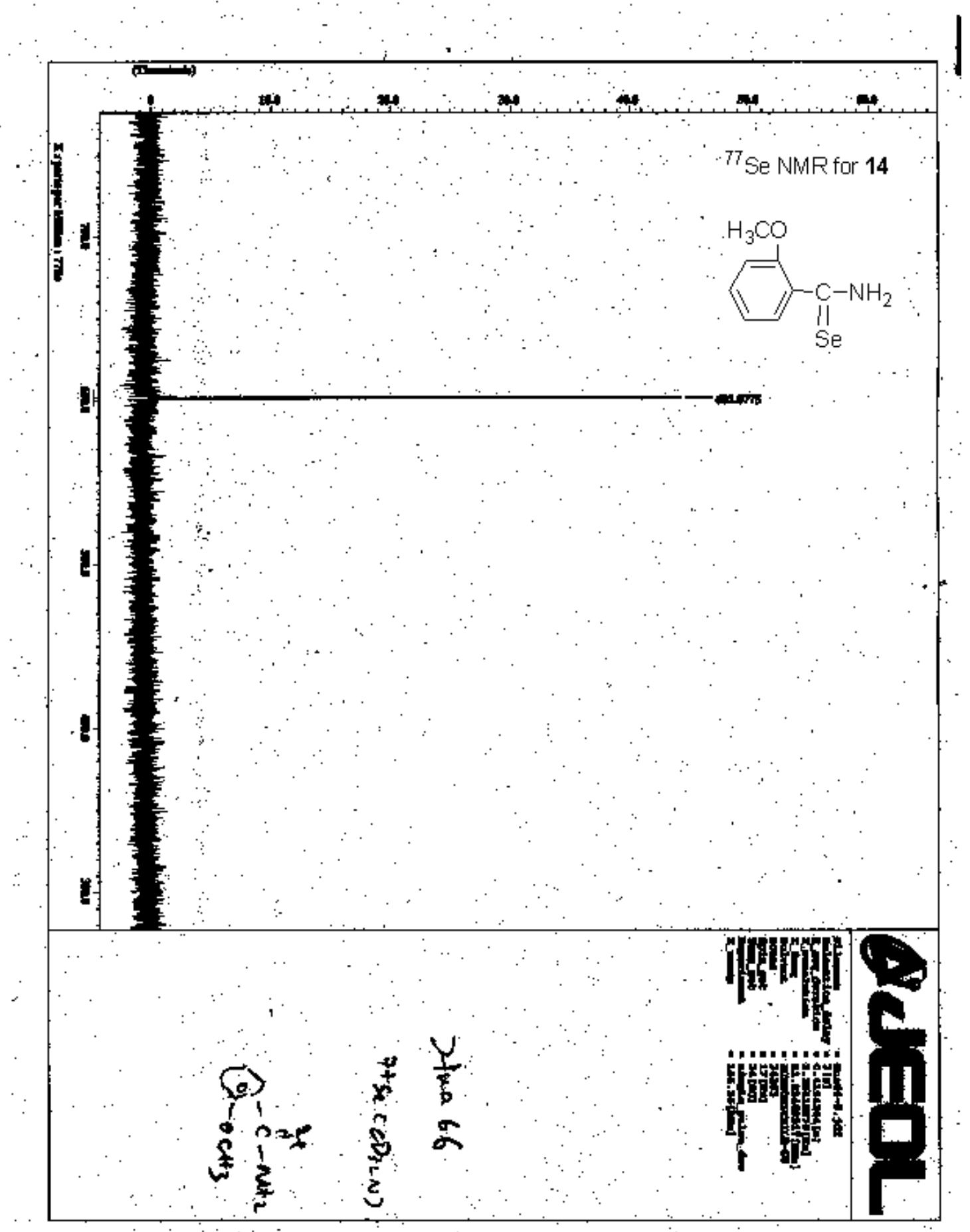




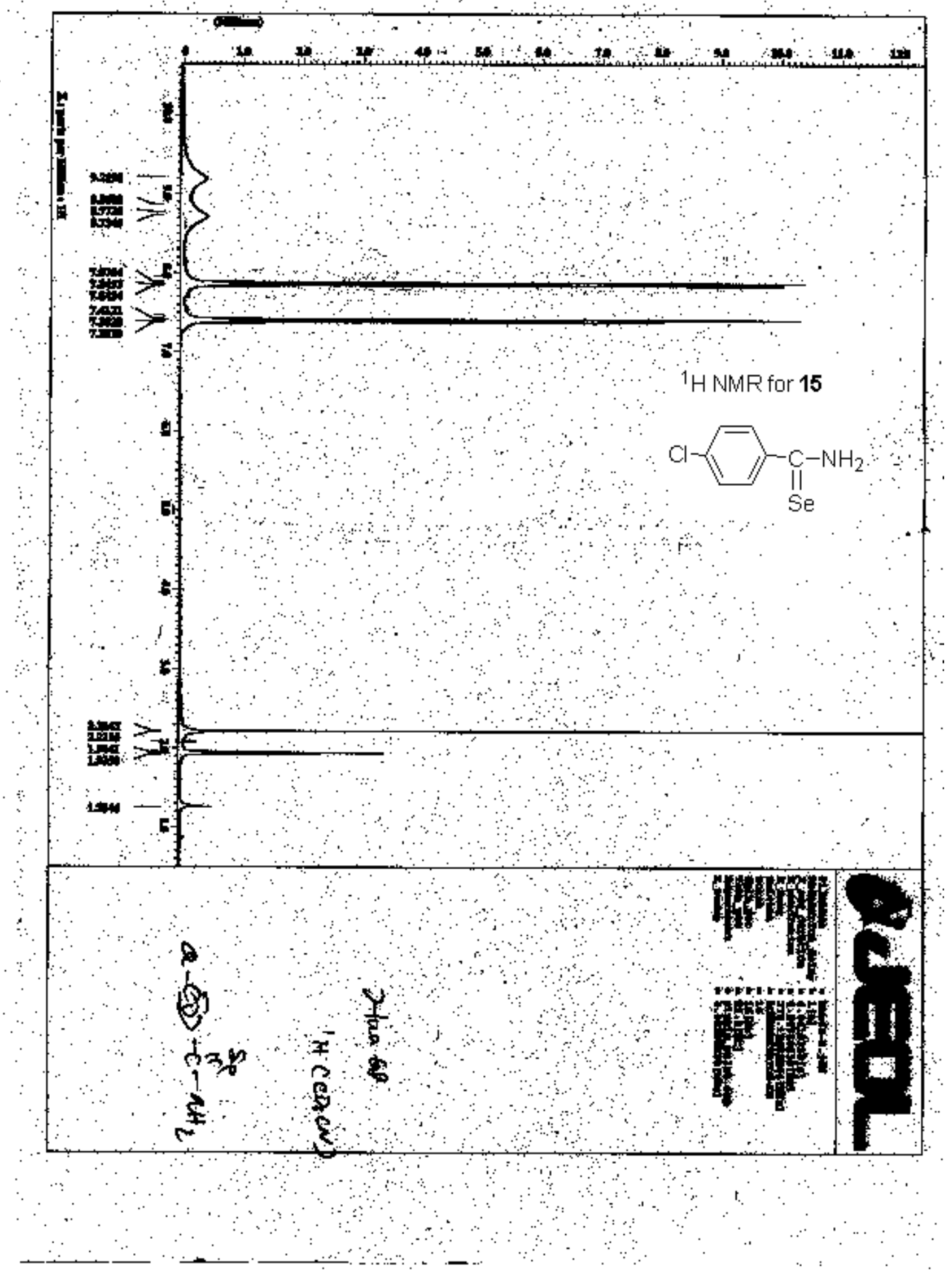




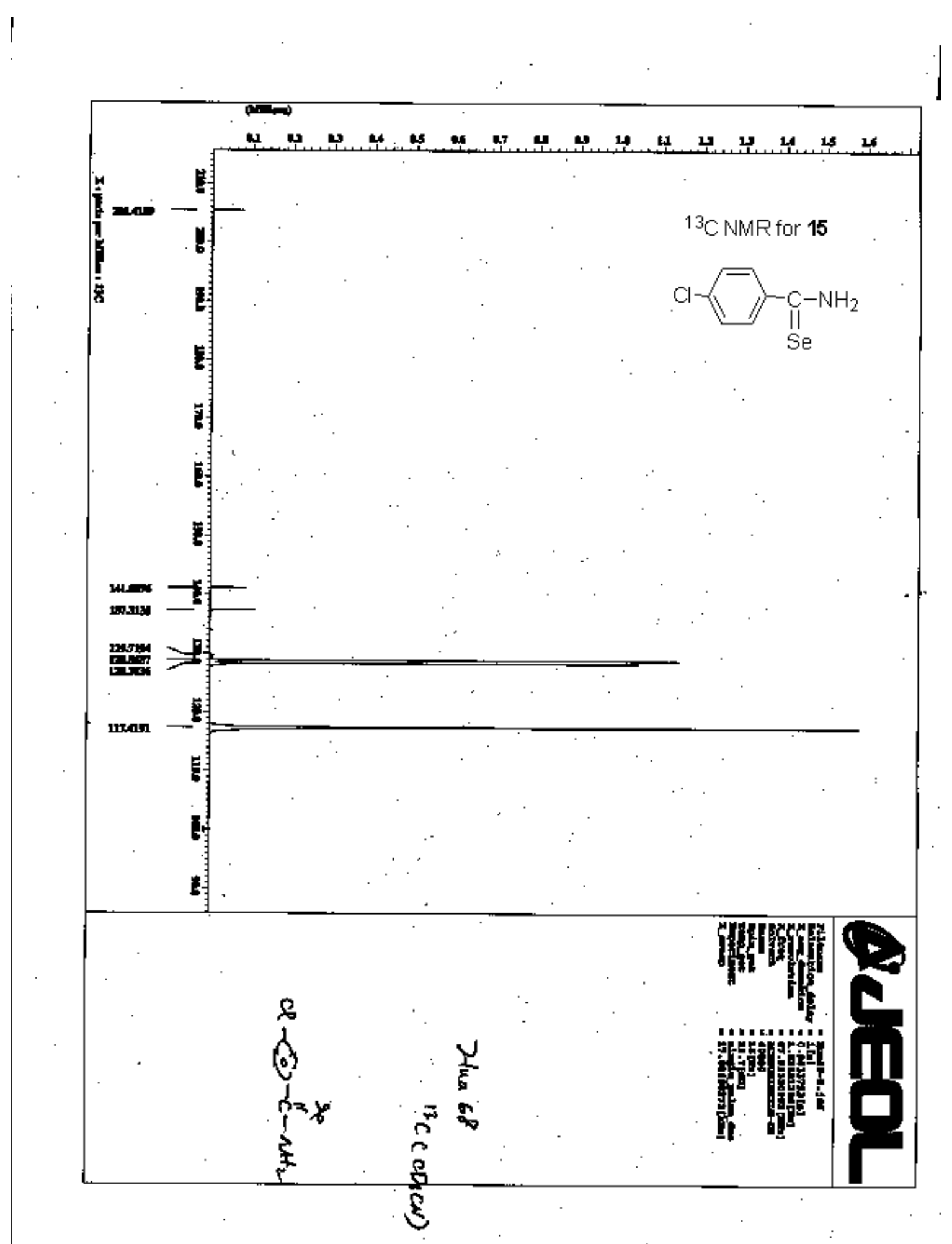




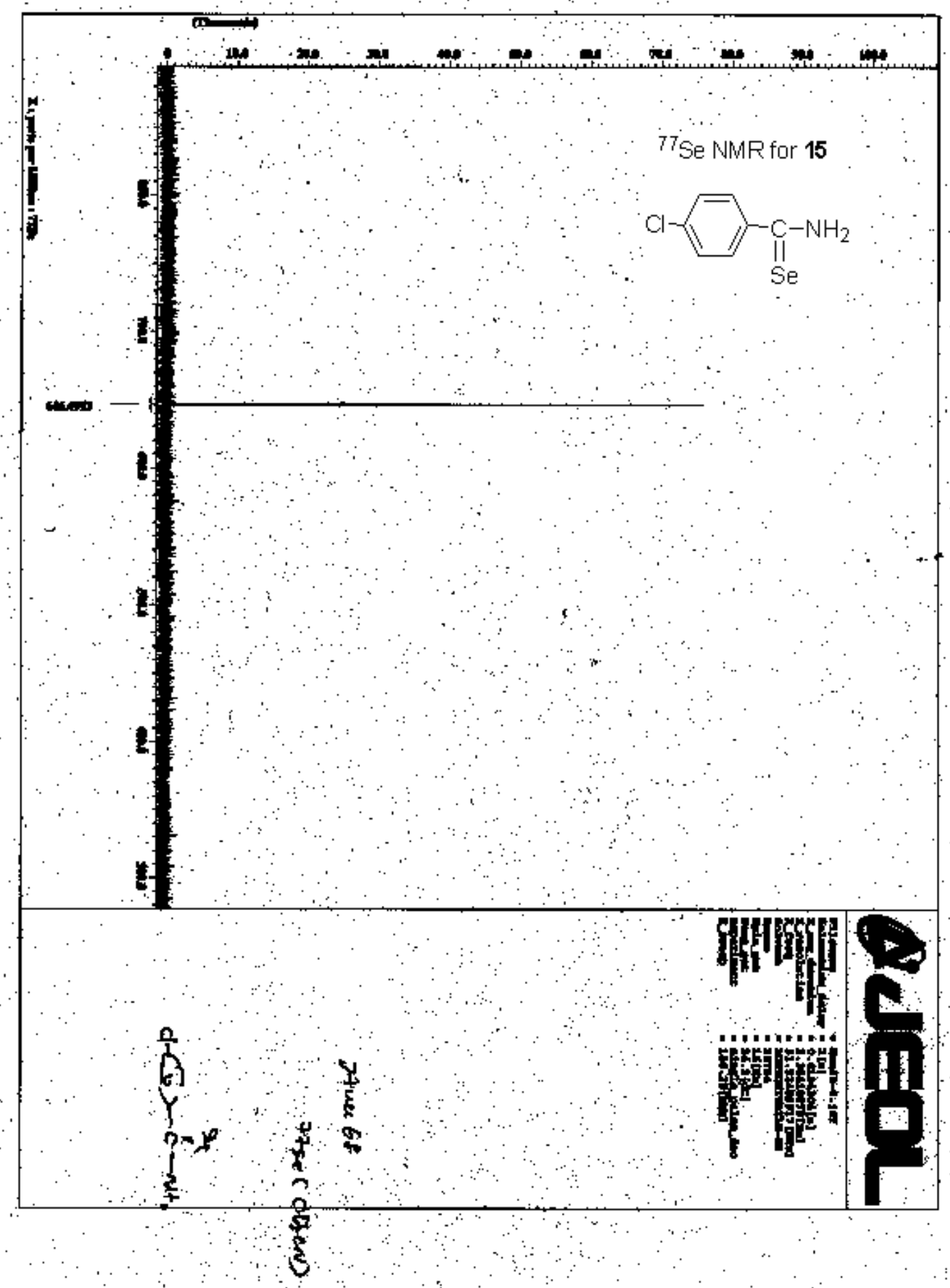




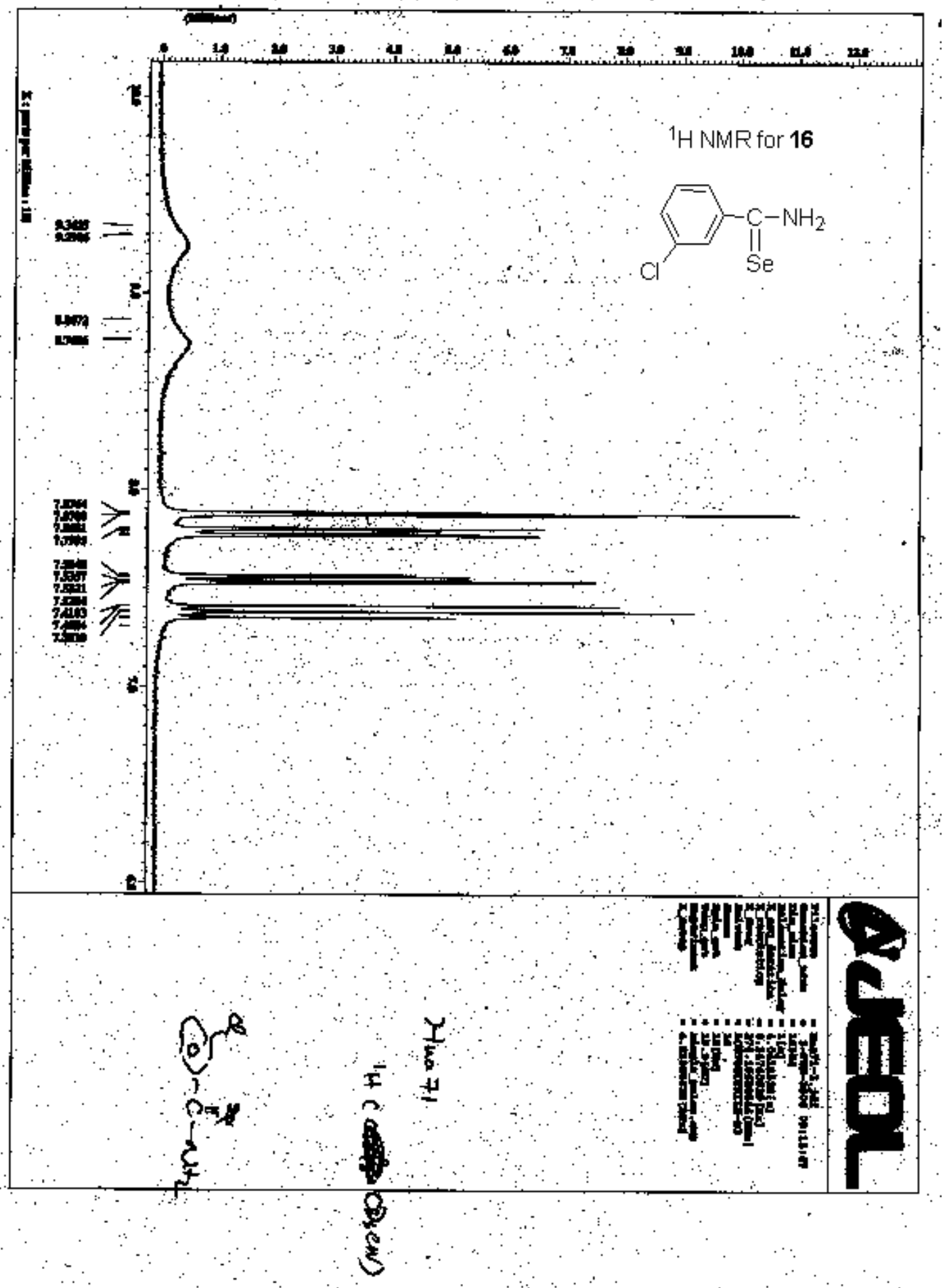




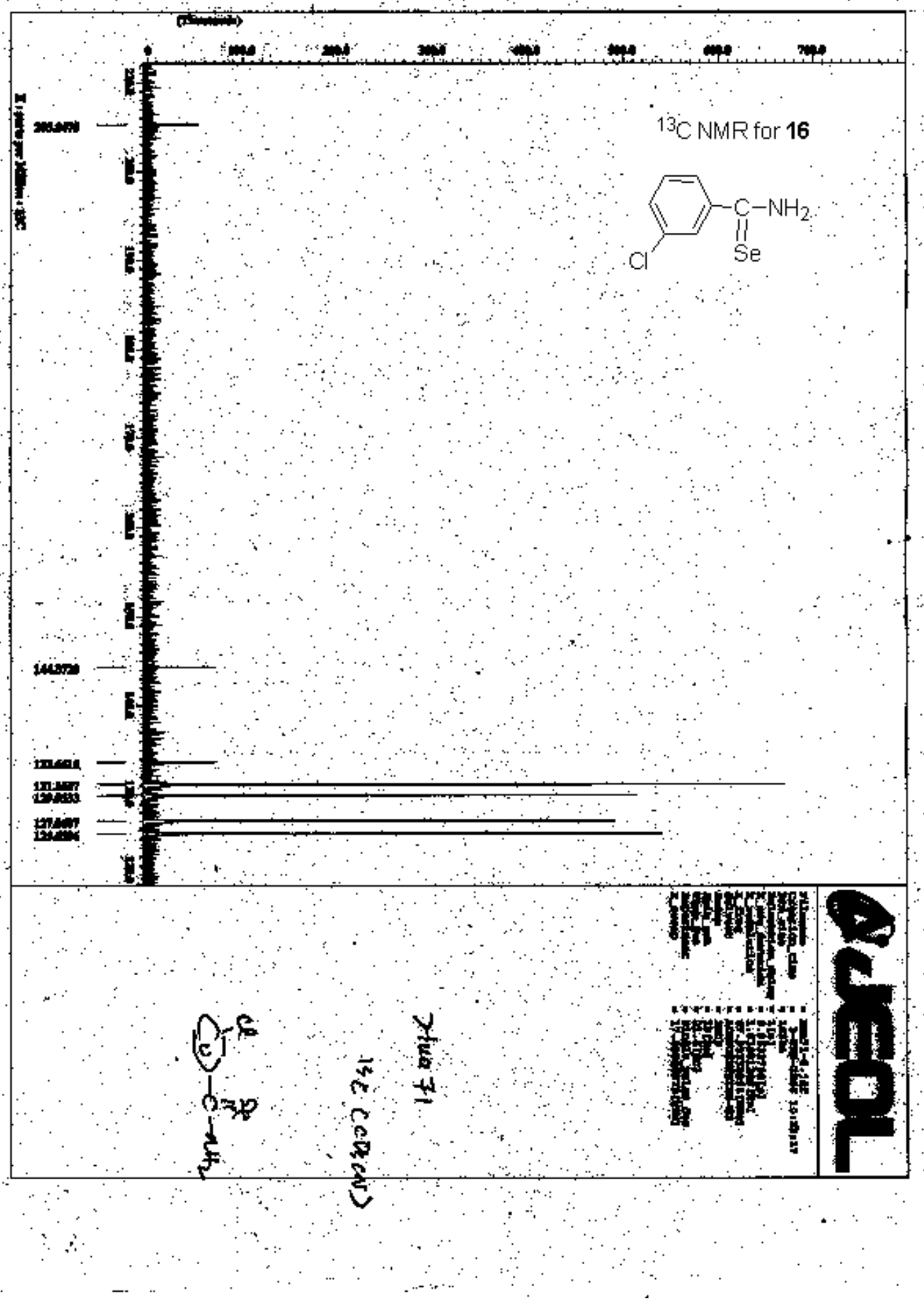




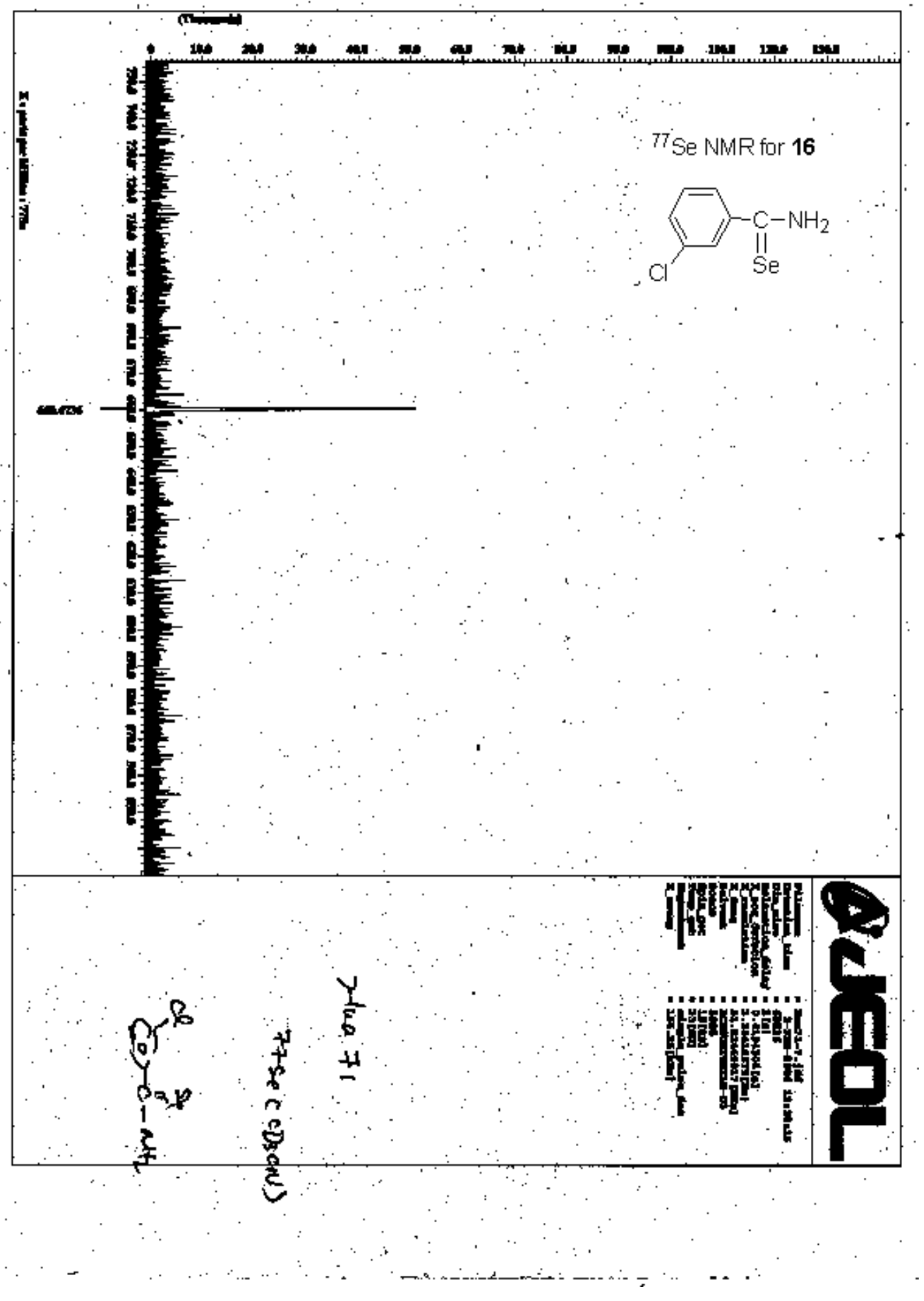




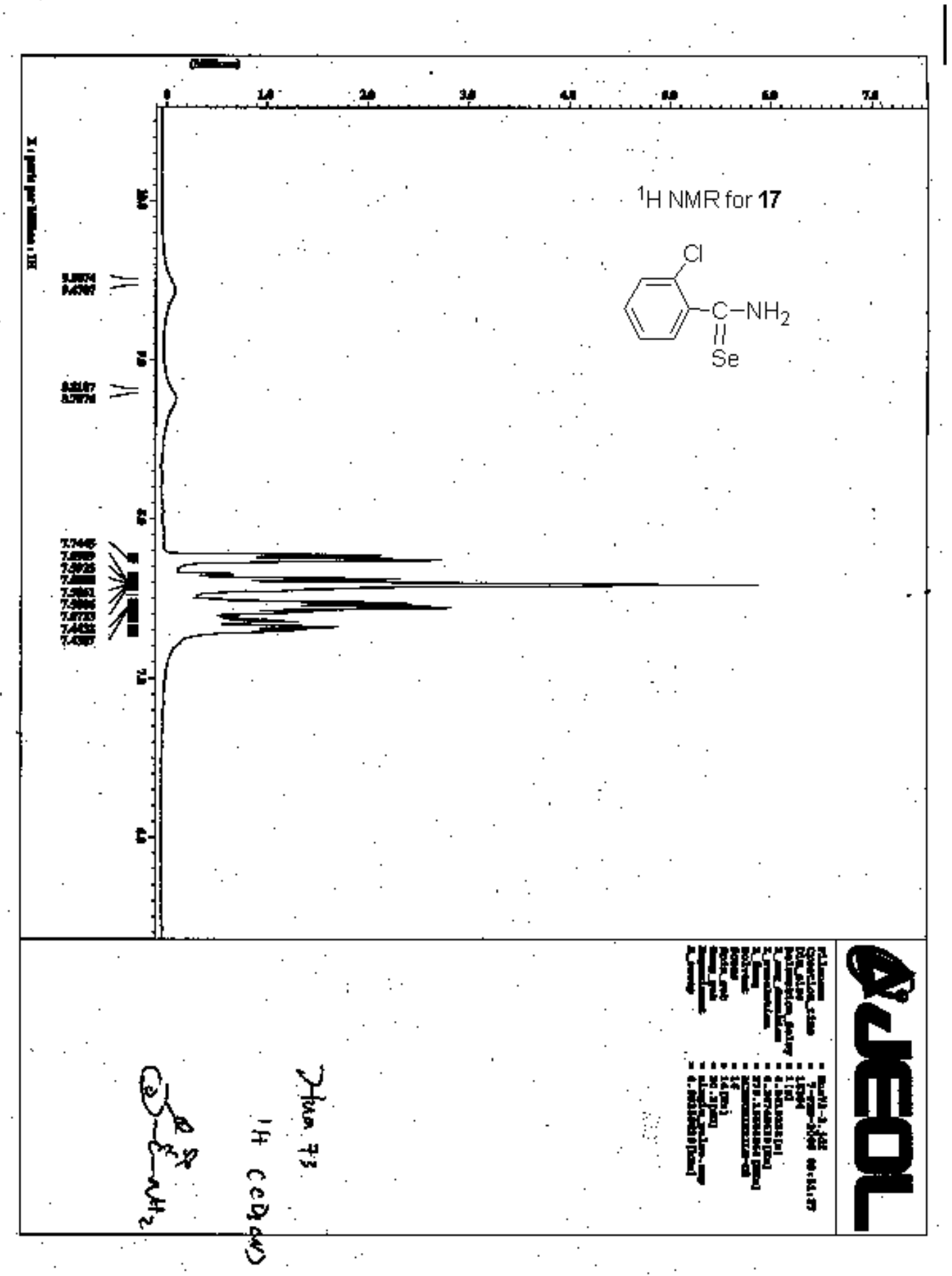




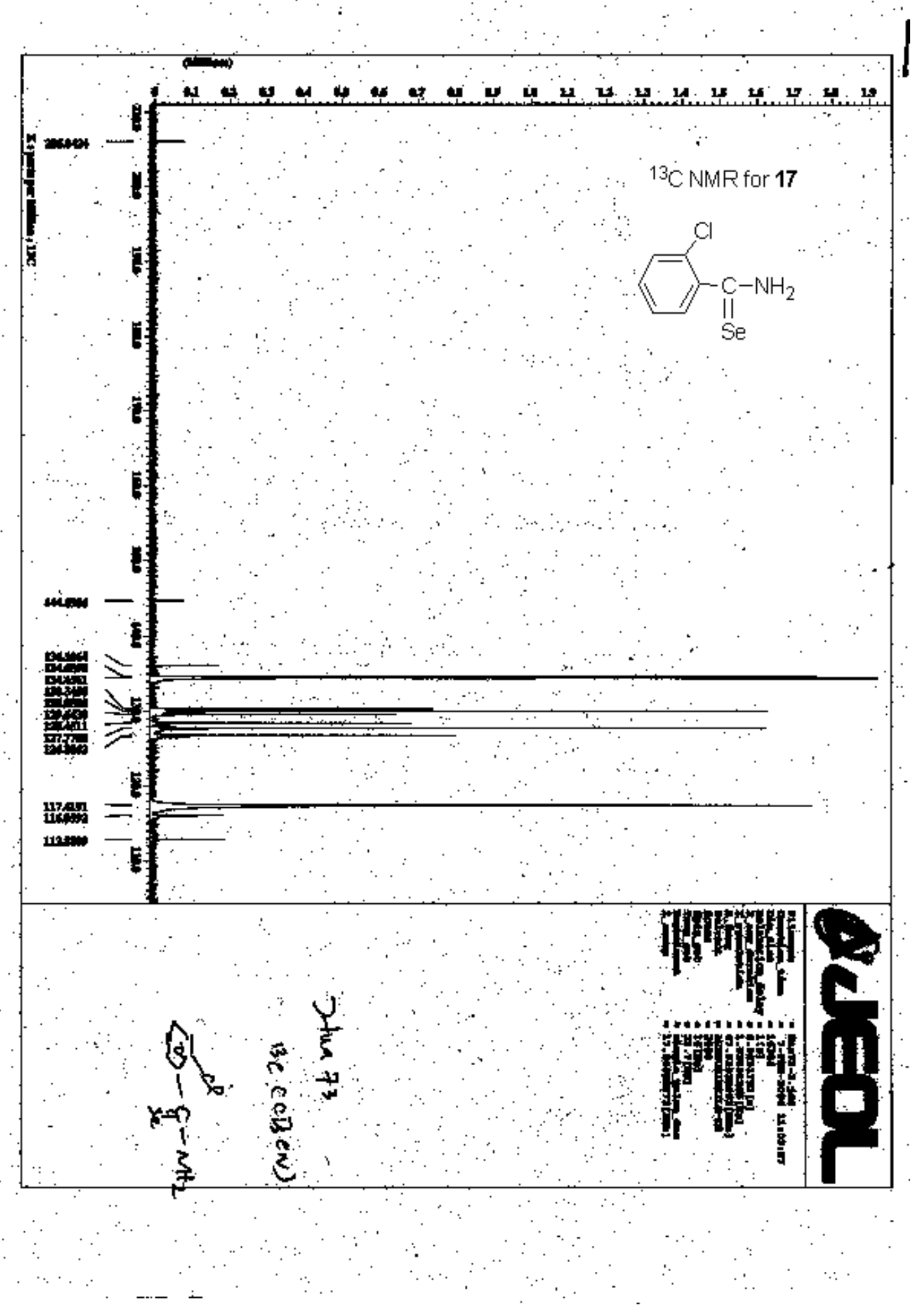




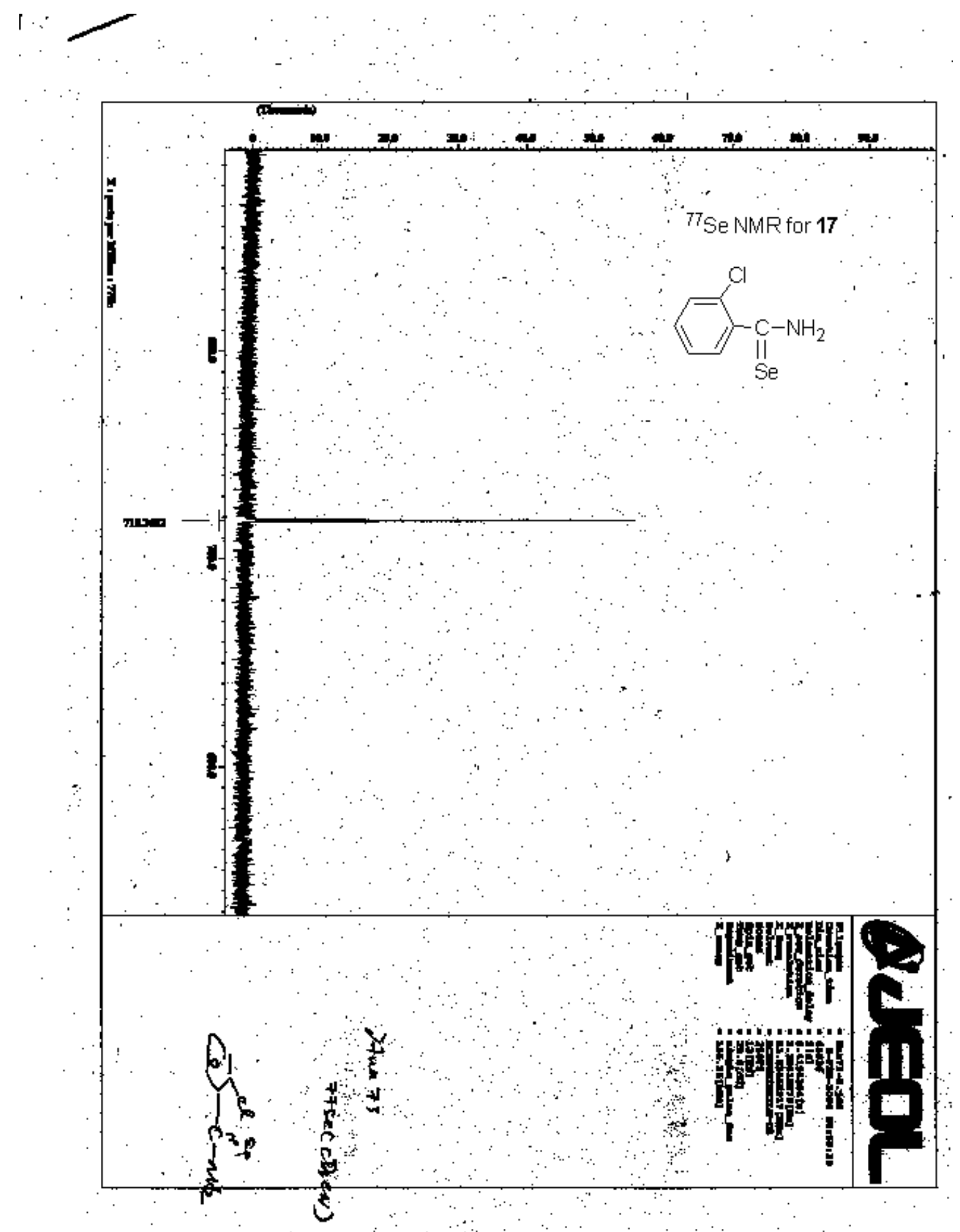




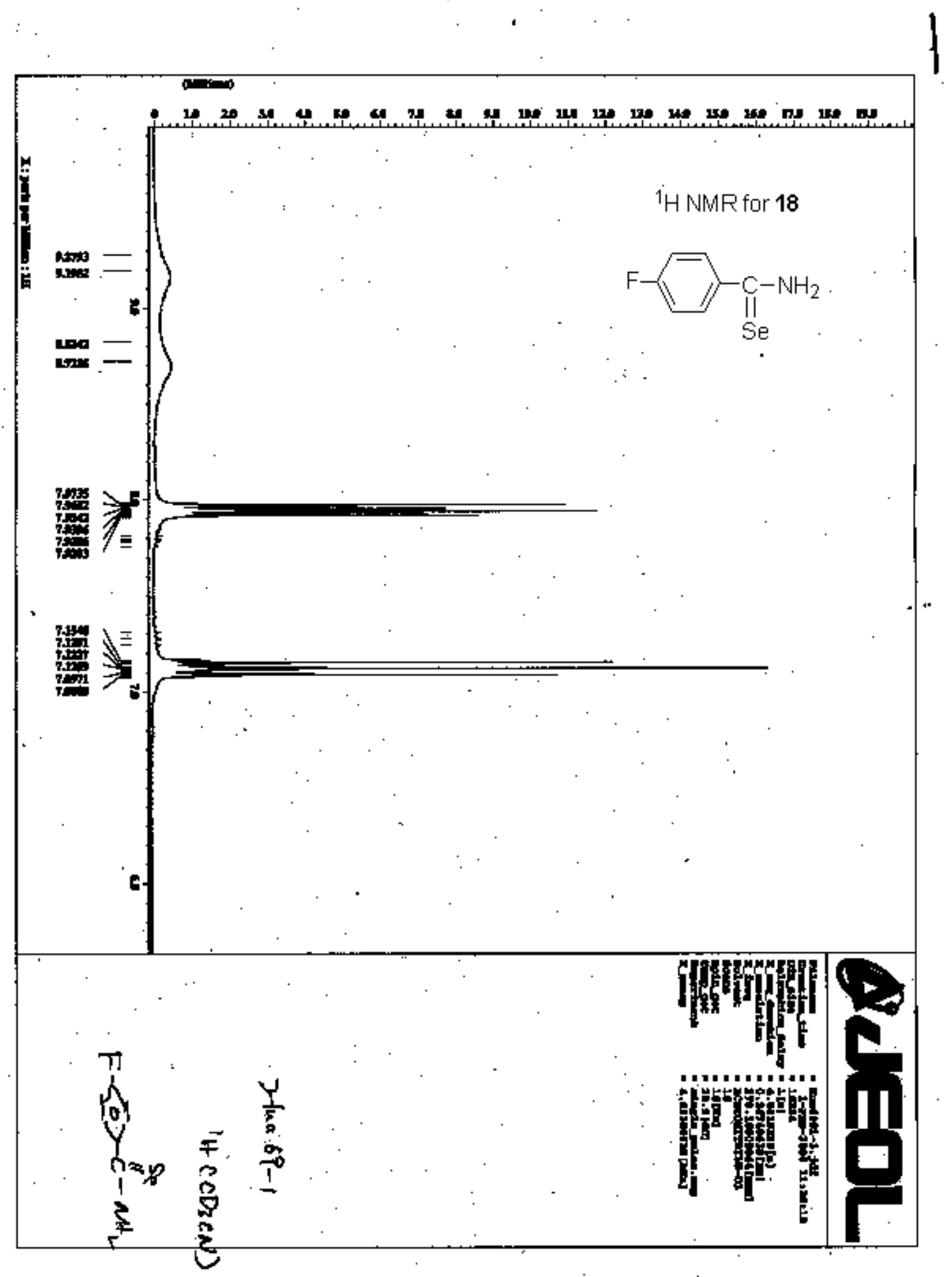




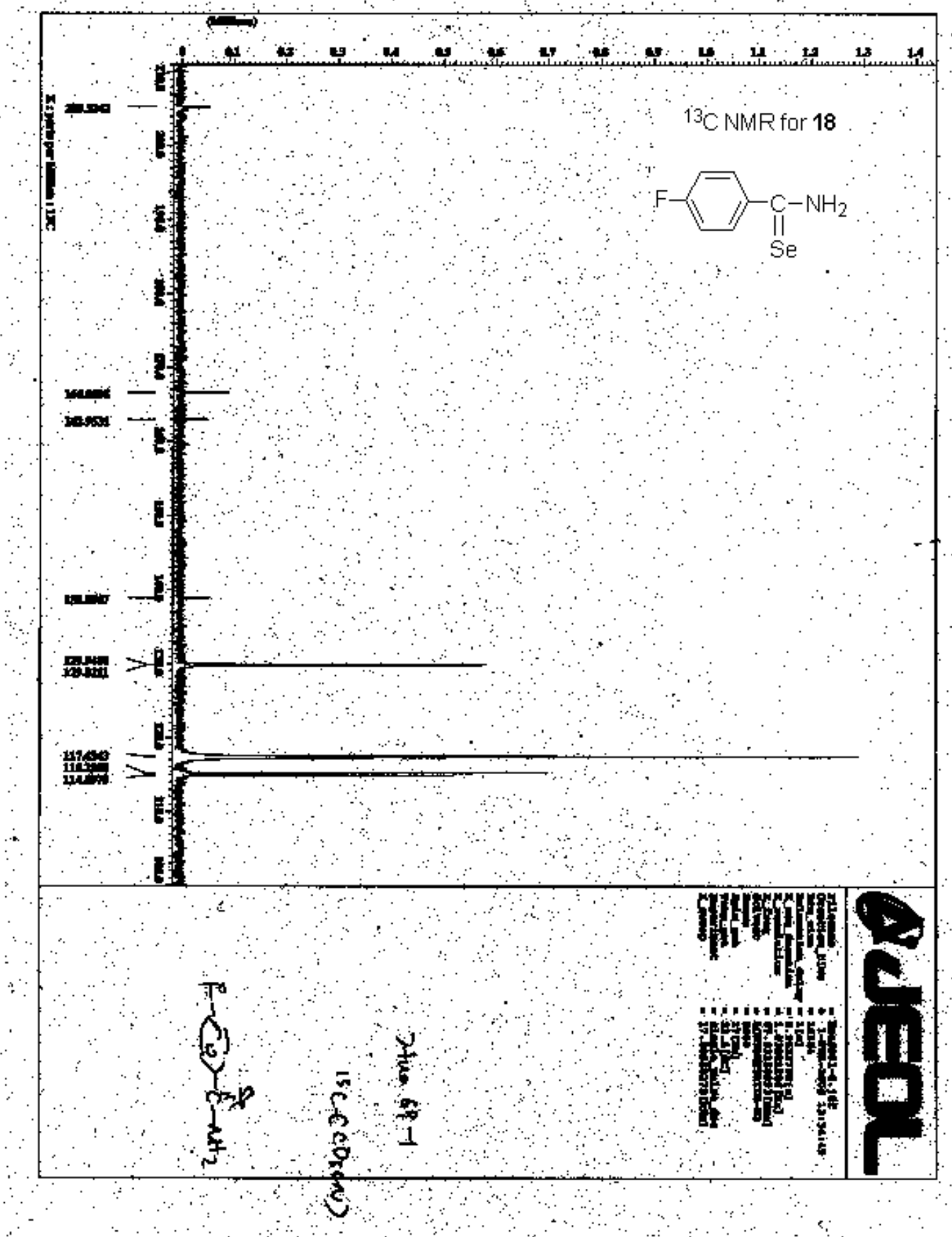




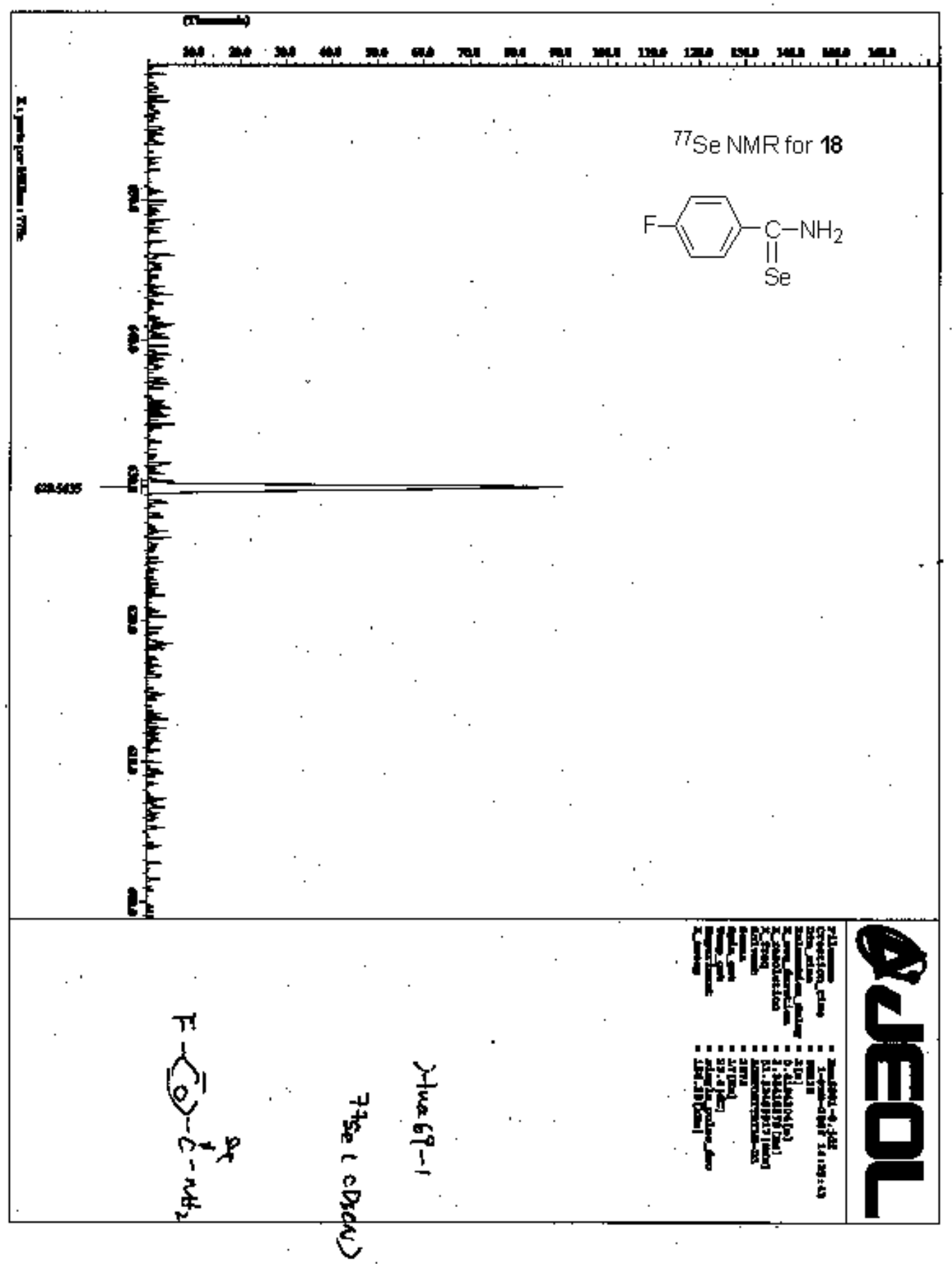




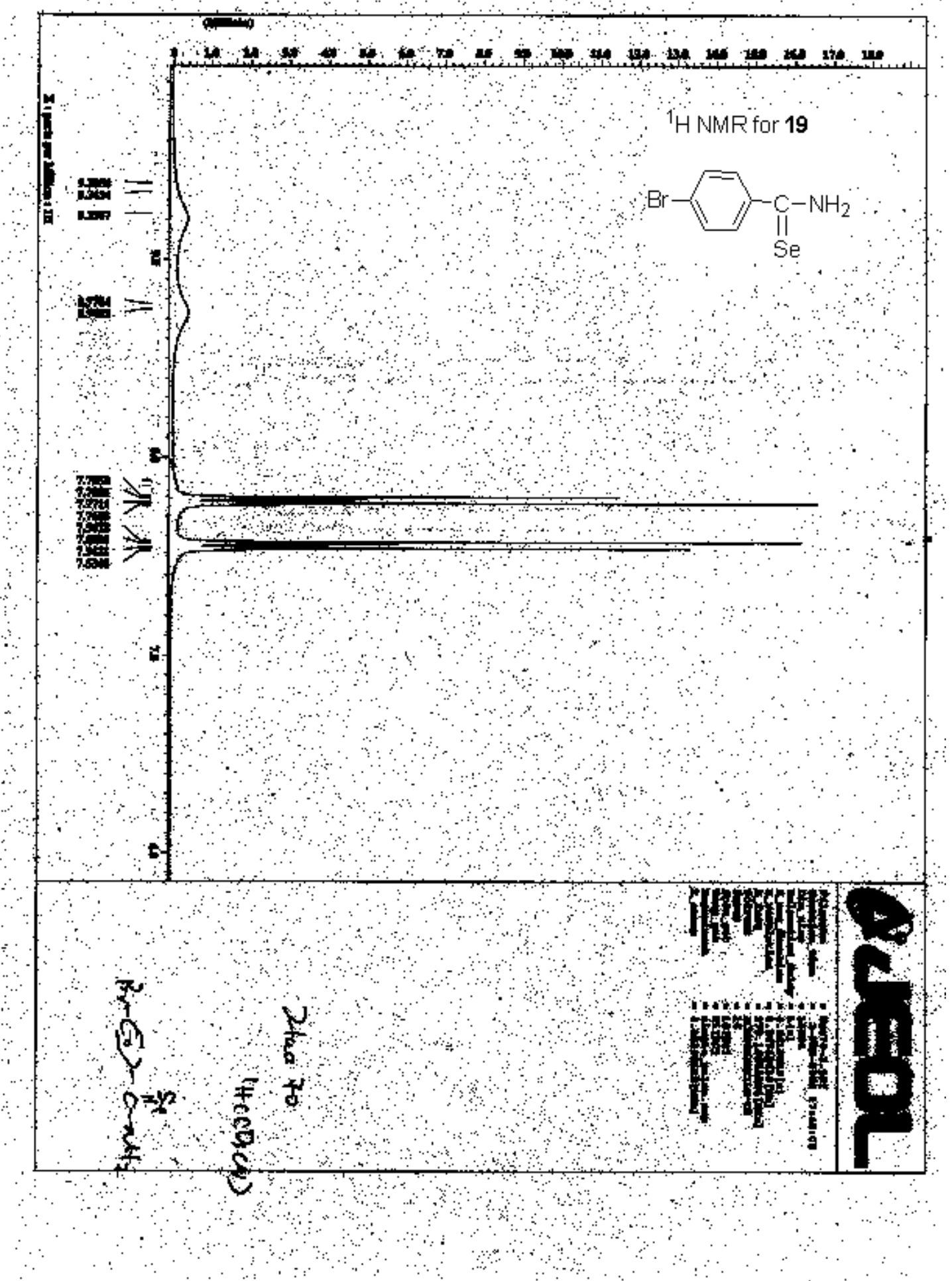




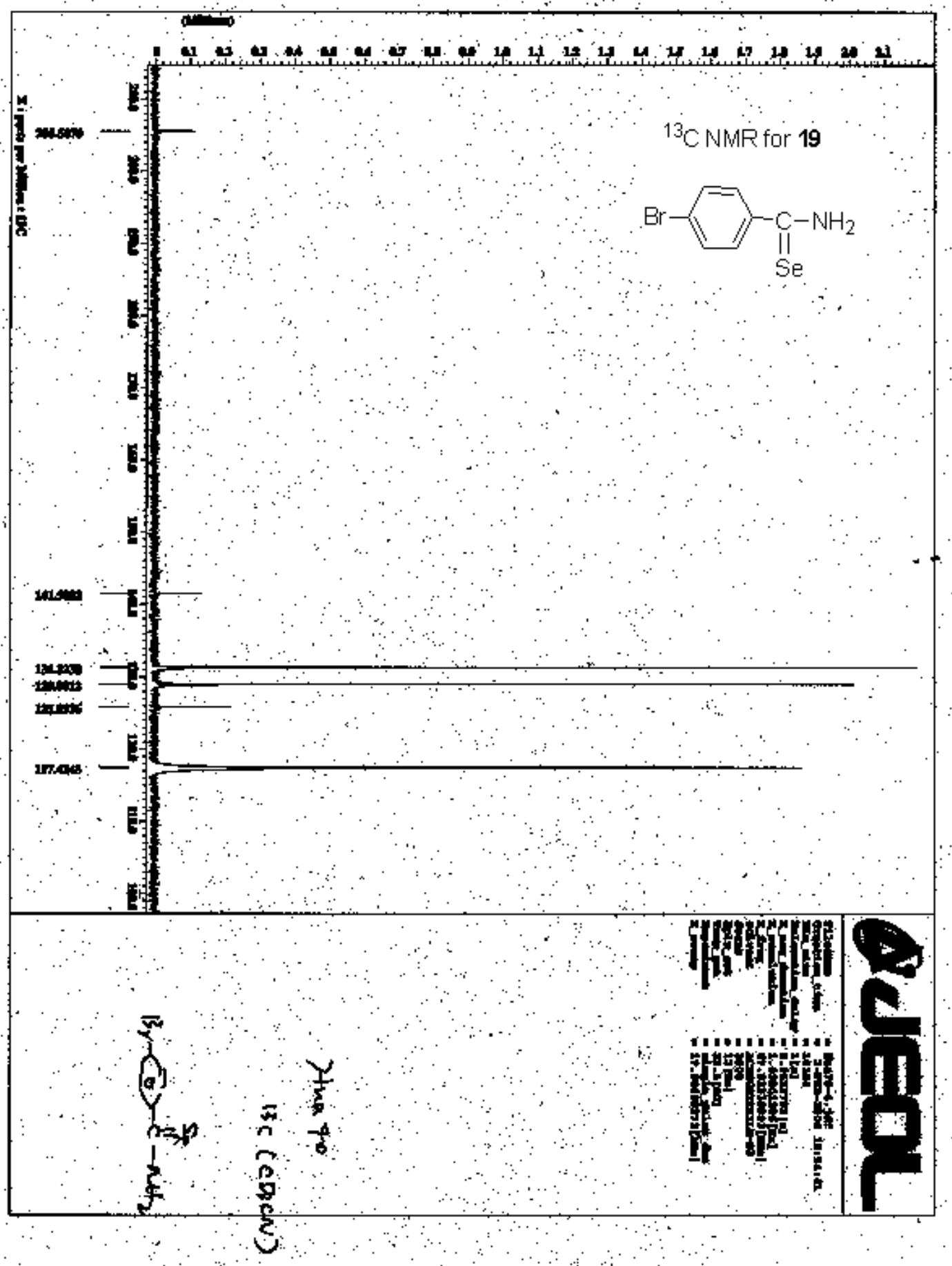




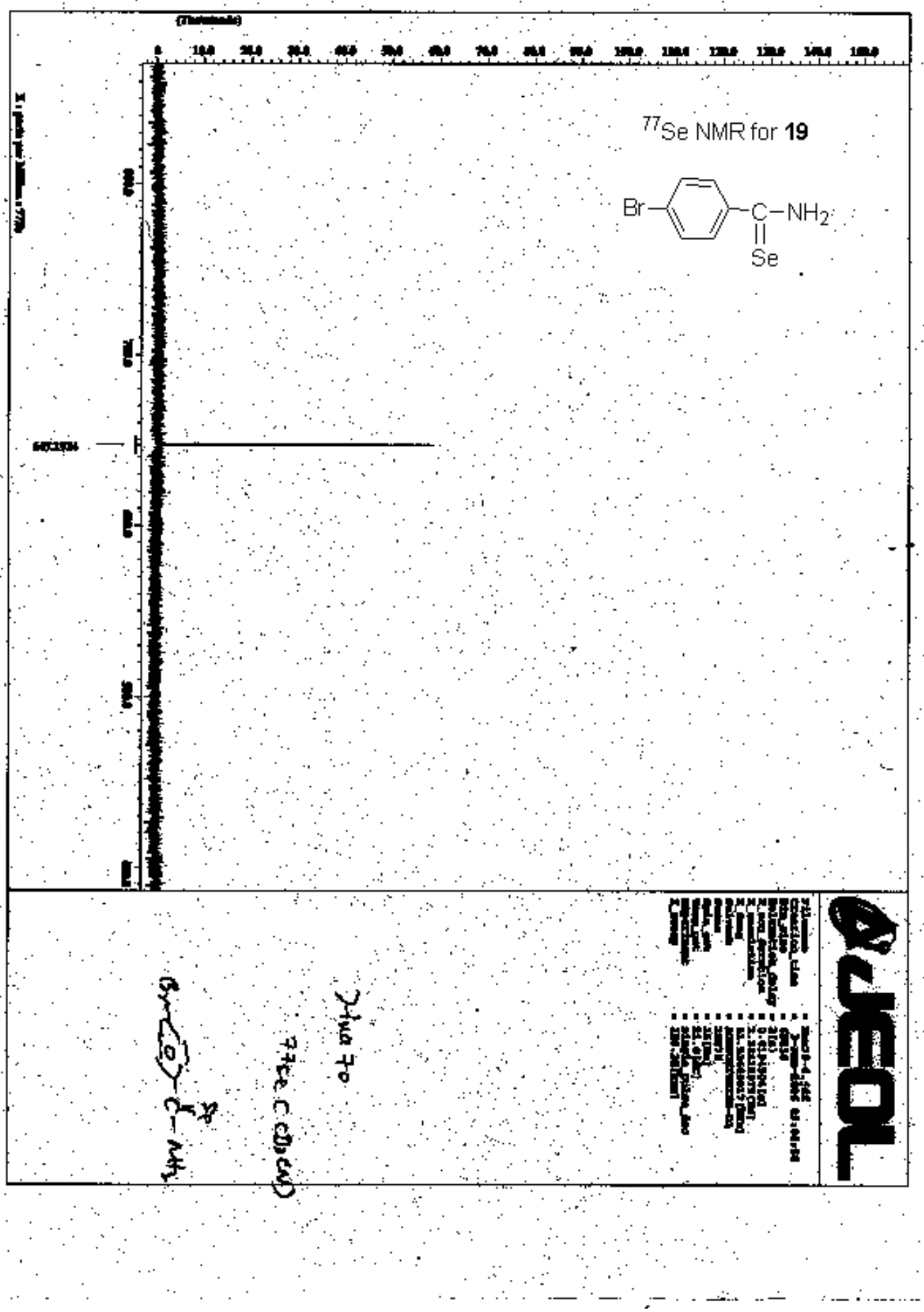

